Unanticipated Side Effects of Successful Quality

Programs: Exploring a Paradox of

Organizational Improvement

Fred Kofman

Nelson Repenning

John D. Sterman

WP\# 3667-94-MSA $\quad$ March, 1994 


\title{
Unanticipated Side Effects of Successful Quality Programs: Exploring a Paradox of Organizational Improvement*
}

\author{
Fred Kofman \\ Nelson Repenning \\ John Sterman $\$$

\section{MIT Sloan School of Management \\ Cambridge MA 02142}

\section{March 1994}

* We are grateful to the people of Analog Devices, particularly Ray Stata and Art Schneiderman, for their outstanding help in this research. They generously provided their data and considerable amounts of their most precious resource - their time. Most important, they approached the important questions here in a genuine spirit of inquiry.

We also thank Gary Burchill, John Carroll, Charlie Fine, Paul Healy, Bob Kaplan, Dan Kim, Tom Kochan, William Pounds, Jim Rebitzer, Peter Schmidt, Marcie Tyre, participants in the 1993 Operations Management Summer Camp and seminar participants at MIT, Harvard and the University of Illinois for constructive criticism and helpful suggestions.

$\S$ Listing of authors is alphabetical; all contributed equally. Comments are welcomed. Please direct correspondence to John Sterman at MIT, E53-339, Cambridge, MA 02142 or jsterman@mit.edu

This work was supported by the Organizational Learning Center, MIT Sloan School of Management 


\begin{abstract}
Recent evidence suggests the connection between quality improvement and financial results may be weak. Consider the case of Analog Devices, Inc., a leading manufacturer of integrated circuits. Analog's TQM program included top management commitment and excellent training. Analog introduced a "Balanced Scorecard" emphasizing nonfinancial measures such as delivery performance, cycle time, wafer yield, and product development time to supplement the traditional managerial accounting system. The TQM program was a dramatic success. Yield doubled, cycle time was cut in half, and product defects fell by a factor of ten. However, Analog's financial performance worsened. To explore the apparent paradox we develop a detailed simulation model of Analog, including operations, financial and cost accounting, product development, human resources, the competitive environment, and the financial markets. We used econometric estimation, interviews, observation, and archival data to specify and estimate the model. We find that employee-based improvement programs like TQM can present a firm with a tradeoff between short and long run effects. In the long run TQM can increase productivity, raise quality, and lower costs. In the short run, these improvements can interact with prevailing accounting systems and organizational routines to create excess capacity, financial stress, and pressures for layoffs that undercut commitment to continuous improvement. We explore policies to integrate improvement programs like TQM with the dynamics of the firm as a whole to promote sustained improvement in financial as well as nonfinancial measures of performance.
\end{abstract}




\section{Introduction}

In 1987 Analog Devices, Inc. (ADI), a leading manufacturer of specialized integrated circuits, initiated a broad-based Total Quality Management (TQM) program. Led by its founder and CEO, Ray Stata, the company introduced TQM into daily activities. Analog created new metrics for defects in manufacturing, distribution and product development, and assessed progress against quality goals for each business unit. Quality improved dramatically: by 1990 defects in outgoing product had fallen by a factor of 10 , semiconductor yield had nearly doubled, and manufacturing cycle time had fallen by half. One would expect such dramatic improvements to boost the competitiveness of ADI's products, and lead to superior growth and profitability. Yet during the same period Analog's share price fell from $\$ 18.75$ to $\$ 6.25$, return on equity fell from $7 \%$ to $-4 \%$ and $\mathrm{ADI}$ was forced into its first-ever layoff. What happened, and why?

The paradox of large improvements in quality that are not followed by financial improvement is not unique. The Wallace Co., a 1990 winner of the Malcolm Baldrige National Quality Award, suffered large losses soon after winning the prize. Despite laying off more than one-fourth of the workforce to cut costs, the company filed for bankruptcy protection in 1991. In a recent study, Ernst and Young (1991) found firms pursuing TQM grew no faster and were no more profitable than comparable firms that hadn't. Interest in the Malcolm Baldrige National Quality Award is falling (Fuchsberg 1993), and press reports skeptical of TQM are appearing (Newman 1991, The Economist 1992, Taylor 1992). The growing evidence that TQM as currently practiced may not lead to competitive advantage or superior financial results stands in stark contrast to the broad diffusion of TQM throughout the corporate and academic world.

The case of Analog Devices is intriguing because it defies all the obvious explanations for TQM's unfulfilled promises. Some argue that TQM doesn't really work, that TQM is merely another management fad (Harte 1992). Yet there is considerable evidence that TQM often results in significant defect reduction and quality improvement. The US General Accounting Office found that quality improved substantially in twenty finalists from the first two years of the Baldrige Award competition (GAO 1991). However, the same study showed these firms realized negligible improvements in return on assets and return on sales.

Another common explanation for the indifferent results of many TQM programs is poor 
implementation. The human resources and organizational development literatures stress that TQM and similar workplace innovations must be integrated with other human resource policies such as employment security and with the overall strategy of the firm (Kochan, Katz, and McKersie 1986, Beer, Spector, and Eisenstadt 1990, Kaufman 1992, Lawler, Mohrman, and Ledford 1992, Beaumont, Hunter, and Phayre 1993, Appelbaum and Batt 1994). Weak leadership, low workforce commitment, inadequate training and support, inadequate metrics or counterproductive incentives can surely dash a program on the rocks of organizational resistance and internal politics. Field studies conducted at MIT have documented many such 'TQM implementation false starts' (Balz and Garberding 1993, Brown and Tse 1992, Ehrler and Jansen 1993, Kim 1993, Kim and Burchill 1992, Peterson and How 1993, Schmidt 1992). Such theories predict that poorly implemented TQM programs will not lead to significant improvement. Yet these theories can not explain the case of Analog Devices - its program produced large improvements in quality and productivity.

An alternative explanation suggests the worldwide recession masked the benefits of $\mathrm{TQM}$. According to this theory, the unexpectedly severe recession in the computer and semiconductor industry beginning around 1989 caused the decline in Analog's profits and share price - Analog's financial decline was simply bad luck. However, these explanations are not sufficient to explain the magnitude of the decline. The recession did slow growth, but during the period after the TQM program was initiated (1987 to 1990) Analog underperformed the semiconductor industry in revenue growth, profit, and net worth (Value Line 1991b).

Analog's TQM experience is paradoxical not because TQM failed to improve operations but because its financial results did not improve after the TQM program succeeded. The resolution of the paradox must lie in the side effects of successful improvement, not in forces that impede change or in external economic events.

This paper explores the causes and consequences of the paradox. How does TQM interact with the organization as a whole? How does it alter relationships coupling the firm to its customers, suppliers, and competitors? How might initial success lead to unintended consequences that slow or thwart continuous improvement? What policies might mitigate such side effects? We will show that without TQM Analog would have been even worse off - TQM 
unquestionably benefited the company. However, improvement programs can create a tradeoff between long and short run effects. Quality programs can quickly boost productivity, augmenting capacity and lowering direct costs. Generating demand to absorb the increase in capacity and reduce indirect costs requires reorientation of basic strategies and capabilities such as product development, sales, and marketing. These complex activities are inherently slow to change, however. Thus the short run effect of successful improvement can be excess capacity. In the short run, improvements in productivity and quality may interact with prevailing accounting systems and organizational routines so that performance is lower than potential.

Our approach involved three steps. First we constructed a detailed history of TQM at Analog Devices using interview, archival and statistical data (section 2). We then generated hypotheses about the decision processes and feedback structures that created that history. Third, we developed a formal simulation model of ADI and its competitive environment to test these hypotheses and explore policies. The behavioral decision rules are based on the field data, and were tested by various means, including econometric estimation (where possible). The model, its empirical support, and validation tests are described in sections 3-4. Analysis shows how successful improvement created excess capacity and lower prices, contributing to lower earnings and market value, which in turn fed back to undermine continued improvement (section 5). We test alternative strategies for the management of TQM (section 6). In the discussion we consider implications of the results for TQM in particular and organizational change programs in general, and conclude with some reflections on the nature of TQM and directions for further research.

\section{TQM at Analog Devices, Inc. ${ }^{1}$}

Analog Devices makes integrated circuits and systems that convert between analog and digital data. Their products are used in equipment such as computer disk drives, compact disk players, and medical instruments. Analog has about 5200 employees and worldwide operations and sales. In fiscal 1992 operating profits were $\$ 26$ million on sales of $\$ 567$ million.

Analog has successfully pursued a strategy of technology leadership, seeking to be the first to market with new products offering superior performance. Analog's strategy enabled it to dominate the high-end niche of the market. From its founding through the early 1980 s sales 
grew at an average rate of $27 \%$ per year. "Then for the first time," as Stata (1989) described it, "we missed our five year goals - and by a country mile." Stata rejected explanations that pinned the blame on the economy. He suspected "that there was something about the way we were managing the company that was not good enough" and concluded "The bottleneck is management innovation." To pursue his vision, Stata helped create the Center for Quality Management, an industry-university consortium dedicated to the development and diffusion of TQM knowledge throughout American industry (Walden and Lee 1992).

In bringing TQM to Analog Stata provided passionate and committed leadership. Analog designed an innovative quality improvement program (Analog Devices 1991), drawing on the principles espoused by many leaders of the TQM movement (Deming 1986, Feigenbaum 1983, Ishikawa 1985, Garvin 1988, Juran 1988, Shiba, Walden and Graham 1993). First, Stata created the office of Quality VP, on the same level as the heads of traditional functions such as engineering and sales. As Quality VP Stata hired Art Schneiderman, an experienced quality consultant. Analog provided training for managers throughout the company. Next they introduced the 'half-life system' (Schneiderman 1988), a method for setting realistic quality targets and monitoring performance against them. Finally, they created a 'balanced scorecard' (Kaplan and Norton 1992) linking these targets to incentive and reward systems.

The half-life system was based on Schneiderman's (1988) finding that, in a wide variety of firms, "any defect level, subjected to legitimate QIP [quality improvement processes], decreases at a constant [fractional] rate...." The result is an exponential decline in defects. The speed of defect reduction can be characterized by the 'improvement half-life' - the time required for defects to fall by $50 \%$.

The basis for the half-life dynamic is the iterative learning loop at the heart of TQM. Participants in quality improvement processes diagnose the root causes of the defects in any process and rank them in order of importance, using Pareto charts and Ishikawa diagrams (Analog Devices 1991). They then design, test, evaluate, and implement solutions using a version of the Shewhart/Deming Plan-Do-Check-Act or 'PDCA' cycle (Shewhart 1939, Walton 1986). The improvement team continues to loop around the learning cycle until they correct the source of the defect, at which point they move on to the next most important defect and begin the 
process again. The fractional rate of improvement can thus be expressed as:

$$
\phi=\mathrm{I} \cdot \mathrm{L}
$$

where $\phi$ is the fractional rate of defect reduction per month, I is the fractional improvement per learning cycle, and $\mathrm{L}$ is the number of learning cycles per month. Fractional rather than absolute improvements per cycle are expected since typical distributions of the causes of defects are not uniform, and the causes with largest payoff are addressed first. Defects at time $t, D$, are then governed by

$$
\mathrm{dD} / \mathrm{dt}=-\phi\left(\mathrm{D}-\mathrm{D}_{\min }\right),
$$

where $D_{\min } \geq 0$ is the theoretical minimum defect level. Thus $\left.D=D_{\min }+\left(D_{t}\right)^{-} D_{\min }\right) \exp (-\phi(t-$ $\left.\left.t_{0}\right)\right)$ and the half-life $t_{h}=\ln (2) / \phi .^{2}$

Improvement half-lives vary across processes and functions. Figure 1 summarizes the relationship Schneiderman hypothesized between the technical and organizational complexity of a process and its improvement half-life. Comparatively simple processes like the functioning of a single piece of equipment on the factory floor were found to have half-lives on the order of a few months. Complex processes like product development had half lives on the order of a few years. Equation (1) explains why this is so: Both the improvement per cycle and the number of cycles per month depend on the technological and organizational complexity of the process to be improved. Improvement per cycle will be large and the improvement cycle will be rapid for simple processes where experiments can be implemented rapidly and the results observed immediately, cause and effect are easily discerned, the process is well understood, problem solving teams involve fewer people from fewer functional backgrounds, and few organizational boundaries and layers are crossed. Conversely, improvement per cycle will be lower, and cycle time will be longer, for processes where experiments are difficult and time consuming, actions have multiple, distant and delayed consequences, the process is poorly understood, problem solving involves coordination and cooperation of many people with diverse skills and interests, and multiple organizations within and outside the firm are involved.

Analog implemented the half-life concept by setting performance targets for product defects, delivery lead time, and on-time delivery performance for the five year plan beginning in 
1987 (table 1). They designed a balanced scorecard that displayed, for each division, the predicted and actual performance on a variety of nonfinancial measures of performance. The scorecard (table 2) summarized financial and nonfinancial metrics in a convenient format, allowing management to evaluate progress objectively. ${ }^{3}$ The scorecard also identified divisions with exceptionally good or poor performance, generating intense internal competition around the speed of defect reduction among the divisions.

By July 1990 Analog had accomplished remarkable results. Defects in product shipped plummeted from 500 to 50 PPM, on-time delivery (OTD) rose from $70 \%$ to $96 \%$, average yield soared from $26 \%$ to $51 \%$, and cycle time fell from 15 to 8 weeks (Kaplan 1990b). Several indicators, however, had not improved. Product development time had not fallen significantly and the stock price had dropped from \$24 in July 1987 to a low of about \$6 in November 1990, a larger drop than that for the semiconductor industry or the market as a whole. In 1985 Operating income was $\$ 46.6$ million. In 1990 , during the recession, it fell to $\$ 6.2$ million. A senior manager estimated that with its depressed market value, Analog could have been acquired for about three years cash flow from operations. Responding to the financial crisis, Analog consolidated some previously separate operations, changed distribution channels, and reoriented product development away from the core business of standard linear integrated circuits (SLICs) towards emerging markets for special purpose chips (SPLICs) and digital signal processors (DSPs). Analog also acquired one of its leading competitors, Precision Monolithics, Inc. (PMI). Analog took an $\$ 18$ million charge for expenses related to the restructuring.

The impact of the consolidation and restructuring on the TQM effort was significant. Responding to the financial crisis, consolidating operations, and managing the acquisition were time consuming for both management and the workforce. Analog sought to avoid layoffs by transferring people to other operations wherever possible, but such transfers took time from TQM activities for the affected workers, their managers and the employees in the divisions to which they were transferred. A senior human resource manager noted that during this time "TQM couldn't get the attention it deserved."

Reorganizing operations to take advantage of the productivity gains generated by TQM was not sufficient to alleviate the financial stresses. In 1990 Analog was forced to reduce 
"worldwide employment by nearly $12 \%$, while simultaneously transferring approximately 150 manufacturing jobs to our low cost assembly and test operation in the Philippines and Taiwan" (1991 Annual Report, 1). These layoffs were Analog's first. While Analog provided extensive outplacement assistance for the affected workers, the effect on morale was substantial. The HR manager recalled "morale was low but we got high marks for our efforts to help people." Nevertheless, the consolidation and layoffs "were confusing and threatening to some people." A manager of the TQM activity in one of the divisions noted "a lot of [employees in a particular plant] were working their tails off for TQM..., and their reward was their [operation] was moved to the Philippines in search of lower cost labor. So [TQM] was another path to a layoff." Schneiderman commented "Up until the layoff the number of QIP teams was steadily growing. After the layoff, TQM stalled. People didn't want to improve so much that their job would be eliminated." By July 1992 OTD fell back to $89 \%$, outgoing defects and average yields stalled at 50 PPM and 49\%, respectively; and product development time had still not fallen significantly (Schneiderman, personal communication). The stock price had increased to about $\$ 9.00$. By 1993 Analog had recovered significantly, with the stock price rising above $\$ 20 /$ share. $^{4}$

\section{The Organizational Dynamics of TQM}

Analog's experience illustrates the complexity of organizational change programs such as TQM. It is difficult to test the many rival hypotheses to explain the impact of organizational interventions such as TQM because it is not possible to conduct experiments with the real organizations. In such settings, models provide a means to explore the likely consequences of alternative policies and environmental circumstances. Capturing complex interventions such as quality improvement programs in a model requires a methodology that can represent the physical and institutional structure of the firm and its markets, that can portray the decision processes of the various actors in the system, including the role of soft variables such as workforce commitment, morale, and fear of job losses, and that can deal with multiple levels of analysis (the shop floor, product development, competitor reactions, the stock market). For these reasons we used the system dynamics method (Forrester 1961, Richardson 1991, Roberts 1978) to guide the development of the theory and build the model. 
We drew on multiple data sources to develop and test the model. We conducted interviews with key participants in Analog's TQM effort and other personnel in product development, TQM, and manufacturing. Other primary sources included internal company presentations and materials, published materials on Analog's approach to TQM, public financial data, and internal data on the various metrics of quality used in the balanced scorecard. Secondary sources such as Kaplan (1990a and 1990b) were used as well. We drew upon established system dynamics models of the firm (e.g. Forrester 1961, Lyneis 1980), prior applications of system dynamics to corporate strategy and organizational behavior (e.g. Abdel-Hamid and Madnick 1991, Hall 1976, 1983, 1984, Morecroft 1985; Roberts 1978), and experimental studies of managerial decision making in complex dynamic systems (Sterman 1989a, 1989b; Paich and Sterman 1993, Lant 1992) to guide formulation of the model and the decision rules for the actors.

The model has a broad boundary (figure 2; table 3 summarizes the major endogenous and exogenous variables). 5 The endogenous variables include physical variables such as orders, shipments, production, wafer starts, finished goods inventories and in-process inventories; financial accounting information including a full income statement, balance sheet and cash flow statement; managerial accounting data such as overhead absorption and labor and materials variances; quality metrics including product defects, manufacturing cycle time, delivery time, on time delivery percentage, and manufacturing yield; motivational variables such as the commitment of the workforce to TQM, the support resources provided for the TQM effort, the workforce's perceived job security, and top management commitment to TQM. The model contains only five exogenous inputs: the producer price index and labor cost index to capture inflation in input costs; a macroeconomic index of the demand for electronic components (capturing the effect of the recession on industry demand); the yield of the S\&P 500 (a determinant of the discount rate investors use to value Analog's expected earnings); and an index of the diffusion of TQM throughout US industry (a determinant of how quickly ADI's competitors can improve as a result of their own TQM efforts). While the model is too large to describe fully here, we discuss two formulations important in understanding the dynamics of TQM: the market demand for ADI's products (a hard variable for which good numerical data exist) and the commitment of the workforce to the TQM program (a soft variable for which numerical data do not exist). 


\subsection{Modeling the Product Life Cycle}

The dynamics of demand are critical to the impact of TQM on Analog. Improvements in product quality and delivery reliability boost product attractiveness, potentially increasing market share in existing product lines. Improvements in product development can speed the introduction of new and better products, creating new markets. Market demand is therefore endogenous to the model. ADI receives a share of the total demand for products in the market segments in which it competes. The attractiveness of ADI's products relative to those of competitors determines market share. For a product of given functionality, a customer judges the attractiveness of ADI's products by considering the price, defect rate, delivery lead time, delivery reliability, and their dependence on individual vendors (the extent to which Analog's customers depend on ADI as a sole source). Attractiveness is nonlinear and falls dramatically if any one of the attributes is particularly poor, even if the others are favorable. For example, if product lead times become excessively large, attractiveness and market share plummet even if price is below the competition. Thus we formulate attractiveness as a multiplicative function of price, defects, delivery lead time, on-time-delivery percentage, and ADI's market share.

The total size of the market for Analog's products depends on the number and market potential of each product in ADI's portfolio. Following ADI's own practice, we disaggregate the product portfolio into two categories: 'breakthrough' products - those products focused on an entirely new market segment; and line extensions - incremental improvements to existing products. The model represents the aggregate of ADI's portfolio of products. We describe the formulation for breakthrough products here; we model line extensions analogously.

The number of breakthrough products on the market, B, increases as Analog releases new products and decreases as Analog discontinues old products. The product development subsystem determines introductions and the average product life, $\tau$, determines discards:

$$
\begin{aligned}
& d B / d t=b^{i}-b^{d} \\
& b^{d}=B / \tau
\end{aligned}
$$

where $b^{i}$ is the rate of product introductions and $b^{d}$ is the rate of product discontinuation.

Market demand for a given product depends on its potential applications. Demand also depends critically on where the product is in its life cycle (Gort and Klepper 1982). Sales of new 
breakthrough products typically rise rapidly, then peak and decline as new products and new technologies supersede them. The total demand for a breakthrough product increases by an amount $\mu$ each time a new product is introduced. Industry demand for that product then grows at a fractional rate $\mathrm{g}$, reflecting the rate of economic growth and the stage of the product in its life cycle. The total demand for breakthrough products, $M$, is the sum of the market demand for each product in the portfolio. We assume that each time a product is discontinued the total potential market decreases by the average sales per product, $\mathrm{M} / \mathrm{B}$. Thus:

$$
d M / d t=b^{i} \mu-b^{d}(M / B)+g M
$$

The fractional market growth rate, $\mathrm{g}$, is a decreasing function of the average age of the product portfolio, $\mathrm{A}$, and rises with the rate of growth of the computer/electronics industry, $\mathrm{g}^{\mathrm{e}}$ :

$$
g=f\{A\}+g^{e}, f^{\prime}\{\cdot\} \leq 0, f^{\prime \prime}\{\cdot\} \geq 0 .
$$

We used the Federal Reserve industrial production index for electronic components as a proxy for demand in Analog's industry. The function $\mathrm{f}\{\mathrm{A}\}$ captures the dynamics of the product life cycle. We estimated equation (6) using a data set ADI provided consisting of annual unit sales categorized by product and vintage for every product introduced between 1970 and 1991 .

Specifically, the fractional change in sales for each observation is estimated by:

$$
\mathrm{g}_{\mathrm{i}, \mathrm{A}, \mathrm{t}}=\alpha+\beta\left(\mathrm{A}_{\mathrm{i}, \mathrm{t}}\right) \gamma+\delta \mathrm{ge}_{\mathrm{t}}+\varepsilon_{\mathrm{t}}
$$

where $g_{i, A, t}$ is the fractional change in sales of product $i$ with age $A$ in year $t$ and $g^{e}$ is the fractional growth in the Federal Reserve index of industrial production of electronic components in year $t$. We estimated the equation by nonlinear least squares. The product age variable is highly significant, while the economic growth term $\mathrm{ge}^{\mathrm{e}}$ is not. ${ }^{6}$ Sales of typical new products grow at about $100 \%$ per year during the first several years (figure 3 ). The fractional growth rate slows as the products diffuse through the marketplace. Products mature after six to eight years, followed by gradual decline until they are withdrawn or replaced by line extensions. While some products may enjoy steady sales for a decade, vigorous demand growth requires the continuous introduction of new products. 


\subsection{Building Commitment to TQM}

A hallmark of TQM is employee involvement: quality improvement teams consist of the same people who do the work (Shiba, Walden and Graham 1993). Thus the improvement halflife depends not only on the complexity of the process but also on the skills, efforts, and commitment of the workforce, as well as the support and training they receive. Generalizing Schneiderman's half-life model, eq. (2), we assume the fractional improvement rate, $\phi$, for a process with defect rate $\mathrm{D}$ is a function of the commitment of the workforce, $\mathrm{C}$. Because changes in product mix, equipment, and employees may render prior improvements obsolete and introduce new defects, quality also decays towards the initial level $D_{0}$ at a fractional rate $\eta$ :

$$
\mathrm{dD} / \mathrm{dt}=-\phi\{C\}\left[\mathrm{D}-\mathrm{D}_{\min }\right]+\eta\left[\mathrm{D}_{0}-\mathrm{D}\right] ; \phi^{\prime}\{\cdot\} \geq 0 \text {. }
$$

The decay term $\eta\left[D_{0}-D\right]$ captures several processes. To the extent changes in operations leading to improvements are embedded in the knowledge of workers or in the capital stock, they may be lost as employees and equipment turn over. Second, changes in customer requirements or the product mix may lead to changes in equipment, operations, and organization that introduce new defects. The fractional decay rate $\eta$ is likely to be low for processes where the improvements leading to higher quality are embedded in physical capital (e.g. changes in plant layout that streamline transfers between workstations) and higher in processes requiring substantial human input (e.g. scheduling delivery dates). Areas where technology or customer requirements are changing rapidly also lead to larger $\eta$. For example, customer delivery requirements change frequently as customer production requirements and product lines change. Thus we assume $\eta$ is small for manufacturing yield, plant cycle time, and process defects, and higher for on time delivery. The decay term means a certain rate of improvement activity is required simply to maintain defects at a given level - that is, there must be ongoing maintenance to compensate for the inevitable changes in the environment and decay of the equipment.

The current commitment of the workforce to TQM is defined as the fraction of the workforce currently applying TQM methods at a high level of commitment and competency. Commitment varies from $0 \leq \mathrm{C} \leq 100 \%$ of a fully committed workforce. We model commitment as a diffusion process driven by both a management-led 'push' and a results 'pull' (Shiba, Walden and Graham 1993): 


$$
\mathrm{dC} / \mathrm{dt}=\theta\left(\mathrm{C}^{*}-\mathrm{C}\right)+\mathrm{wC}(1-\mathrm{C})
$$

The first term in eq. (9) captures management's 'push'. When management initiates a TQM program the commitment of the workforce rises gradually, at a fractional rate $\theta$, towards $\mathrm{C}^{*}$, the commitment and competency achievable through the leadership and training provided by management. The effectiveness of management's efforts to promote TQM, $C^{*}$, depends on how much attention management can devote to TQM. The attention devoted to TQM by management is endogenous. For example, $C^{*}$ falls when other issues, such as dealing with financial stress, demand more of management's attention. The second term represents the 'pull' effect generated by successful results. The more people are involved in TQM efforts, the more they will communicate their enthusiasm to others through word of mouth, presentations, and other encounters with colleagues. Thus the pull effect is proportional to the current commitment level and the word of mouth effect, w, creating a positive feedback loop by which commitment can be self-generating (provided word of mouth is favorable). The impact of word of mouth is necessarily limited as commitment approaches $100 \%$ by the term (1-C).

Word of mouth can have a positive or negative impact on commitment. We model the sign and strength of the word of mouth effect, $w$, as depending on the perceived improvement resulting from TQM ('does it work?'), the adequacy of the support for TQM provided by management ('is help available; will TQM effort be rewarded?') and the security and stability of the workforce ('if we don't cut costs and move product I might lose my job, so I don't have time for TQM', or 'with this reorganization going on, I don't have time for TQM'). The overall impact of these factors is mediated by the average intensity of communication in the organization, $\omega$. Thus

$$
w=\omega\left[f_{r}\{r\}+f_{a}\{a\}+f_{s}\{s\}\right]
$$

where $f_{r}\{r\}$ is the impact of results, $r$, on word of mouth; $f_{a}\{a\}$ is the impact of the adequacy of management support, a, on word of mouth; and $f_{s}\{s\}$ is the impact of perceived job security and stability, s, on word of mouth. The nonlinear functions $f\{\cdot\}$ may be positive or negative. For example, when TQM effort yields strong evidence of improvement (when $r$ is high), the positive word of mouth encourages others to begin to their own TQM efforts. As perceived improvement declines, the benefits of TQM are less obvious and less effective in persuading colleagues to 
jump on the TQM bandwagon. Thus $\mathrm{f}_{\mathrm{r}}\{0\}=0, \mathrm{f}_{\mathrm{r}}\{\cdot\}>0, \mathrm{f}_{\mathrm{r}}{ }^{\prime} \geq 0$, and $\mathrm{f}_{\mathrm{r}}{ }^{\prime \prime} \leq 0$ for $\mathrm{r}>0$.

Support resources also affect workers' attitudes towards TQM. TQM initiatives require support from management in the form of assistance with tools and process, rewards and recognition. Resources such as time or staff are needed to enable people to participate in TQM and still do their normal jobs. We model the adequacy of support resources, a, as the ratio of the support available to that required. Support requirements are proportional to the rate of TQM effort and thus to commitment. Support resources depend in part on management's focus: as management shifts its attention to financial firefighting and organizational restructuring, managerial attention and support for TQM falls. The assumed relationship $f_{a}\{\cdot\}$ is an s-curve such that $f_{a}\{1\}=0$ and $f_{a}{ }^{\prime}\{\cdot\}>0$. Finally, worker perceptions of job security and stability affect attitudes towards $\mathrm{TQM}$. If workers are threatened or overburdened by layoffs and reorganizations, if they are preoccupied by the turmoil caused by financial crisis and pressures to cut costs, word of mouth will be negative. We define job security and stability from 0 (financial stress, consolidation and/or layoffs cause severe turmoil) to 1 (workers have confidence in the stability of the current organization and do not fear layoffs). Thus $\mathrm{f}_{\mathrm{s}}\{1\}=0$, and $\mathrm{f}_{\mathrm{r}}\{\cdot\}<0$ for $0 \leq \mathrm{s}<1$.

The interplay of leadership, results, support, and job security thus determines the dynamics of commitment. For example, the introduction of TQM by management creates some commitment, stimulating initial improvement efforts. Provided support resources are adequate and job stability is high, strong early results of the improvement effort will encourage others to participate in TQM, leading to still greater results. Commitment will diffuse rapidly, reach a high level, and defects will fall. However, if rising commitment takes too much time away from people's primary jobs, or if the productivity gains created by improvement lead to reorganization and job losses, the negative effects of inadequate support and low morale could overwhelm the effect of results and cause commitment to fall. Thus the feedbacks from the diffusion of commitment to the rest of the organization are critical. These feedbacks are captured endogenously in the full model, and as will be seen, play a crucial role in the dynamics of TQM at Analog.

\section{Comparison to Historical Behavior}

Model testing in system dynamics emphasizes a wide range of tests, including tests of model structure as well as correspondence with historical behavior (Forrester 1961, Forrester and 
Senge 1980, Barlas 1989). The model's structure and parameters were verified through a series of meetings with various Analog executives and managers. The robustness of the model was assessed through extreme conditions tests. The structures important to understanding the impact of TQM on Analog and assessing policies are endogenous so feedback effects and possible reactions to policies are captured. We conducted a variety of sensitivity tests, both of parametric sensitivity and sensitivity to the level of aggregation. We used partial model testing (Homer 1983 ) to test the structure and parameters of each major subsystem in the model (e.g., product development, the share price). In partial model testing the endogenous inputs to each subsystem are replaced with the corresponding historical data. Significant deviations from historical behavior in the output of the subsystem reveal formulation or parametric errors.

We then assessed the ability of the full endogenous system to replicate the data. We consider various goodness-of-fit measures including the mean absolute percent error (MAPE) between simulated and actual data and the Theil inequality statistics (Theil 1966). The Theil statistics partition the mean square error between model and data among three components: bias (unequal means of simulated and actual data); unequal variation (unequal variances); and unequal covariation (imperfect correlation between the two series). Sterman (1984) shows how these components of error can be used to diagnose formulation flaws in simulation models.

The simulation begins in 1985; most of the historical data run through $1991 .^{7} \mathrm{We}$ assess the historical fit of the model against twelve variables for which time series data were available, including financial and operational measures (table 4, figures 4-5). The fit of the model overall is quite good. The MAPE ranges from $3 \%$ to $22 \%$ and $\mathrm{R}^{2}$ ranges from .69 to .99 . The fits for unit sales, revenue, cost of goods sold, R\&D budget, and cumulative new products introduced are excellent, with $\mathrm{R}^{2} \geq .89$, mean absolute percent errors $\leq 7 \%$, low bias and low unequal variation. The operational measures of performance - yield, defects, on time delivery and cycle time - have more variation than the aggregate measures, so the MAPE tends to be slightly larger. Still, yield, cycle time, and OTD have MAPE $\leq 11 \%$ and $\mathrm{R}^{2}>77 \%$, and the majority of the error is unsystematic noise for all three. The MAPE for defects is $20 \%$, but the $\mathrm{R}^{2}=.93$ and there is negligible bias (the comparatively large error is due to the assumption that TQM starts at the same moment in all activities, while actual start times differed). Model fits for the share price 
and for market value/cash flow, a measure of vulnerability to takeover, are quite good, with MAPE $=.12$ and .17 , respectively, $\mathrm{R}^{2}=.81$ and .79 , respectively, and negligible bias and unequal variation error. The largest error is in operating income, with $\mathrm{MAPE}=22 \%$ and $\mathrm{R}^{2}=$ .69. Operating income is the small difference of two large numbers (revenue less cost), so small errors in revenue or cost create much larger percentage errors in income. While unbiased, simulated operating income has a slightly lower variance than the actual data, which are quite noisy. Overall the model's ability to replicate Analog's experience endogenously, from the factory floor to the financial markets, is good.

\section{Results: Base Case}

TQM in the simulations begins on 1 January 1987 with the creation of the office of the VP for Quality, the introduction of the balanced scorecard, and training in TQM methods for managers and the workforce. 8 These activities raise commitment to TQM (figure $6 a$ ), leading to initial quality improvement efforts in various divisions. At first, job security and stability is high and resources are ample to support the relatively few initial efforts (figure $6 \mathrm{~b}, 6 \mathrm{c}$ ). The improvements flowing from these initial efforts are widely publicized throughout the company, leading to positive word of mouth that increases commitment still further. As more and more people throughout the company jump on the TQM bandwagon, defects begin to fall throughout the manufacturing organization (figure 5).

As the number of improvement teams grows and TQM diffuses throughout Analog, management support becomes inadequate. At the beginning Art Schneiderman and his small staff could provide extensive guidance, support, and cheerleading to the small number of initial projects. As TQM diffused, however, line managers throughout the firm were called on to provide support for improvement teams in their areas, and continue to do their normal jobs as well. However their training, experience, and available time were not always adequate, and the quality of support fell (figure $6 c$ ).

Management attention is also limited and must be allocated among competing demands. In the model managerial attention is allocated differentially as a function of perceived improvement in different sectors. The quality VP said "some people saw the value of TQM right away, 
but the majority needed to see results before committing themselves, and a few resisted and could never be persuaded. We needed to demonstrate that TQM worked for Analog to bring the skeptical majority on board, so we spent a lot of our time on projects we thought would succeed early on." Thus we assume managers turn their attention towards areas in which improvements become visible quickly. The result is a pair of positive feedback loops which reward the areas improving faster with the support they need to improve still more, while starving the slow improving areas of resources, further impeding their progress. In the model, as in reality, improvement came first and quickest in manufacturing, and was slower in product development and other management functions. As discussed above, Schneiderman expected this to be so: the half lives of operations-level processes, with relatively low technical and organizational complexity, were expected to be a few months while the half-lives for complex processes like assessing customer requirements and developing new products were expected to be several years. Thus the manufacturing area receives a larger share of support resources from 1987 through 1990 as it demonstrates the quickest results (figure $6 \mathrm{~d}$ ).

Commitment to improvement in the product development area lags behind manufacturing, since results have not yet been observed and inadequate support leads to frustration. Schneiderman said "Many engineers didn't think TQM could improve product development and thought it interfered with their autonomy. The requests for help we received came primarily from the operations side." Stata was more blunt: "There is some closeted cynicism about quality in the company. Among the engineers, it isn't even closeted. They think it's crap" (Jacob 1993). Due to poor support and low commitment reported product development times do not exhibit appreciable improvement, despite the potential to fall with a half-life of 24 months (figure 6e).

To stimulate demand, Analog had to restructure its strategy and capabilities to align better with changes in technology, competition, and customer needs. These efforts included shifting R\&D effort towards SPLICs and DSPs, attempts to speed product development, and changes in distribution channels. Intrinsically greater complexity means improvement half-lives for these activities are long, limiting the short-run impact of strategic reorientation on demand.

Thus efforts to speed new product development and reorient Analog's capabilities to better meet changing customer needs could not stimulate demand fast enough to match the 
improvement in capacity caused by faster cycle time, higher yield, and fewer defects. However, improvements in product quality and delivery lead to higher product attractiveness. If higher quality allowed Analog to capture additional market share sales might rise enough to match the increase in effective capacity. This was not the case. Analog's simulated market share rises slightly until early 1988 but then falls back despite the large increase in product quality (figure 6f). There are several reasons for the failure of higher quality to generate permanently higher market share. First, Analog's share in some of its key markets was already very high. Some customers were reluctant to further increase their dependence on Analog as a sole source supplier. ${ }^{9}$ Second, Analog's competitors were not standing still. TQM knowledge is not privately appropriable. Through benchmarking, conferences, training, and consultants TQM knowledge diffuses rapidly, so competitor quality improves and prices fall. Indeed, Stata helped create the Center for Quality Management precisely to increase the adoption of TQM throughout the business community, including the electronics industry; through his publications and speeches he stimulated many firms to adopt TQM earlier than they might have. Thus the attractiveness of the competitor's products rises along with Analog's (though with a lag). The industry-wide improvement in quality generated benefits captured by Analog's customers rather than rents or market share advantage for Analog.

As TQM boosted capacity and productivity, Analog's unit production costs dropped. Our interviews indicated that, as in many firms (see e.g. Cyert and March 1963), Analog sets prices by marking up unit production costs by a standard percentage. The traditional markup ratio, a little over $200 \%$, was sufficient to cover indirect costs per unit and provide a reasonable return. The traditional markup changed only slowly. Thus as unit costs fell so did average prices. Between 1985 and 1989, unit production costs fell by about 16\%, and average selling prices fell by just over $17 \%$ (table 5 ). However, indirect costs per unit fell only slightly. R\&D, sales, marketing, distribution, and management, the activities driving indirect costs, all have high technical and organizational complexity. They have intrinsically longer improvement half lives than the manufacturing activities driving unit production costs. Further, as discussed above, commitment to TQM in these areas was low, slowing improvement below the already low potential rate. By 1989 unit indirect costs had fallen only 9\%, much less than the drop in unit production costs. 
Though falling in absolute terms, indirect costs became a larger fraction of total costs. Analog's traditional gross margins were no longer sufficient to cover indirect costs and yield a reasonable profit. Operating income per unit fell by $45 \%$ (table 5 ). ${ }^{10}$

Analog's stock price fell as earnings dropped and as investment analysts responded to the rising indirect cost fraction by criticizing what they took to be ADI's apparent lack of cost control. Value Line's reports were typical:

"... we caution our readers that this company has a history of frequent earnings disappointments." (Value Line 1991a)

"Sales may be difficult to predict, but it is hard to understand why Analog can not cope with this problem by adjusting expenses accordingly." (Value Line 1991b)

"Analog needs to develop cost control ability to match its technological skill and sales growth. The company has enjoyed fairly steady revenue increases...Its earnings record has been inconsistent enough, however, to make one think that Analog's priorities are not what investors seek."(Value Line 1992)

Between 1987 and 1990 the simulated stock price falls (figure 4) as revenue growth slows, earnings decline, and the simulated capital markets grow concerned about ADI's high costs. As share prices fall, the ratio of Analog's market value to cash flow drops below 6 years (figure $6 \mathrm{~g}$ ), making Analog vulnerable to takeover attempts (a hostile acquirer could pay off the cost of gaining 51\% control with just three years of current cash flow). The pressure to boost the share price by cutting costs and trimming excess capacity led Analog to consolidate many operations and lay off about nine percent of its workforce. In the model, the financial stress leads to layoffs in mid-1990, roughly the same timing as in reality. Managing the consolidation and assisting those who lost their jobs all take time away from TQM activities, and the anxiety and confusion caused by the layoffs hurt morale. Job security and stability plummet (figure $6 \mathrm{~b}$ ) and commitment to TQM in manufacturing falls (figure 6a). Improvement stalls, and on time delivery falls back from its peak (figure 5). With quality stagnant but the competitors' still improving, Analog's competitive position deteriorated. Schneiderman recalled: "In 1989, thanks to our TQM program, we made it to number one on H[ewlett] P[ackard]'s list of top ten suppliers. After TQM stopped in 1991, we became number two on their list of ten worst suppliers."

The base case shows that TQM unquestionably benefited the company. Rapid improvements in yield and cycle time boosted productivity, lowered unit costs and roughly doubled 
Analog's production capacity. But TQM also created unanticipated side effects. The side effects arise from the interactions of TQM with the accounting system, with organizational norms and routines, and with the expectations and behavior of other organizations such as the financial markets. For example, TQM caused manufacturing yield to double in just three years. But in the short run, as yields rose above the historical levels used in production scheduling, excess inventory accumulated. Attempts to speed new products to market clashed with goals for lower cycle time and higher on time delivery, since running test lots of new products often requires the same equipment needed to make current products. Management's desire to build commitment to TQM by demonstrating early results focused attention on operational issues and slowed progress in new product development, contributing to excess capacity.

Most important, improvement was faster in operations and slower in R\&D, marketing, distribution, and management. Thus TQM disrupted the traditional relationship between direct and indirect costs, relationships embodied in organizational norms for price setting. Because unit production costs fell faster than indirect costs, the traditional markup was no longer adequate to cover indirect costs, leading to lower operating income, lower stock prices, financial stress, and ultimately, to layoffs.

\subsection{Analog Devices in 1993}

Thus the very success of TQM creates imbalances and side effects that can feed back in the short run to undermine commitment to continuous improvement. At Analog the side effects of successful improvement were severe, even threatening Analog's survival as an independent firm. Analog did survive, however, and by mid 1993 had recovered significantly. In 1990 Analog acquired Precision Monolithics, one of its competitors. With lower costs and a modest recovery from the recession, net income in 1992 had grown to $\$ 15$ million on sales of $\$ 567$ million. The stock price in May 1993 had rebounded to about $\$ 20 /$ share, a rise of more than $300 \%$ from the trough in 1990, compared to a rise of about $45 \%$ for the S\&P 500 as a whole. The simulated Analog recovers as well, even without the acquisition - though without the possibility of a takeover either. A weaker firm, or a firm experiencing these difficulties when capital to fund takeovers was more readily available, might not have survived.

TQM at Analog has rebounded as well. Our interviews show that morale among 
employees has recovered significantly from the lows of 1990-91. A second wave of TQM activity is underway. Unlike the first wave, current efforts emphasize improvements in product development and the other drivers of indirect costs. Stata is personally involved in many of these quality efforts, chairing the quality steering committee and attending the annual 'QIP-fests' gatherings where TQM successes and methods are shared. These meetings have attracted growing numbers of teams since they began in 1990, and a growing fraction of these teams come from engineering, sales, and administration. Market research firm Dataquest recently named Analog "the best midsize semiconductor supplier for the second year in a row" (Jacob 1993, 67).

Most of these recent developments were predicted by the model. Figure $6 \mathrm{~b}$ shows simulated job security and stability recovering after 1991 as improving financial results boost morale. As morale recovers, a second wave of TQM begins in the model around 1992 (figure 6a). The second wave in the model, as in reality, stresses improvement in product development and the other drivers of indirect costs: commitment to TQM in product development rises swiftly after 1992 (figure 6a) and management support for TQM is more evenly balanced between product development and manufacturing (figure $6 \mathrm{~d}$ ). The simulated stock price rebounds from its 1991 lows to about $\$ 12 /$ share by the end of 1992 , close to the actual value (figure 4h). It is important to note that these developments in the simulation arise endogenously and emerged from the model before the evidence for the rebound of TQM activity and recent financial improvements were available.

\section{Policy Tests}

\subsection{Analog does not implement TQM}

The base case shows how Analog's success in reducing defects in their operations, coming just as the economy weakened and competition intensified, was not sufficient to prevent financial stress, downsizing, and consequent collapse of commitment to TQM. The obvious question is then 'what would have happened if Analog had not implemented TQM?' Figure 7 shows the result. This simulation is identical to the base case except that TQM is never implemented. Without the productivity gains stemming from TQM, Analog's costs and investment needs remain high, reducing competitiveness. Schneiderman commented that "When I arrived 
we were expecting to have to build a new wafer fab for about $\$ 100$ million. We still haven't had to build it because yield doubled." Further, though ADI stimulates competitors and customers to pursue TQM in the Base Case, they eventually adopt TQM on their own even when Analog does not. As competitor quality outstrips ADI's, and as customers demand their suppliers meet higher standards for quality, reliability, and cost, the simulated Analog quickly loses market share. By the beginning of 1991 revenues fall $75 \%$ from base case levels and the stock price plummets due to large ongoing losses. The simulated Analog is forced to begin major layoffs in 1989, earlier than the base case. Without TQM the company would most likely have been taken over or forced to exit the industry. While the speed of the decline in the simulation is sensitive to the assumed rate at which competitors adopt TQM, there is little doubt that Analog's competitors and customers would have pursued TQM even if Analog did not.

The No-TQM case shows that TQM yielded significant benefits to Analog despite the difficulties and stresses it created. Indeed, it had to be done. We now explore different policies Analog might have pursued to integrate TQM better with the rest of the organization and build sustained commitment to continuous improvement.

\subsection{Maintaining the No-Layoff Policy}

One of Deming's (1986) precepts for success is to "drive out fear." Since commitment to TQM was eroded by the 1990 layoff and the consequent fear that productivity improvements would lead to job losses, we test a policy in which Analog maintains its traditional no-layoff policy (the workforce may still decline through attrition). The goal is to keep commitment and morale high so that improvement continues - employees know that ADI will not lay them off, regardless of any excess labor capacity.

In the short run performance is worse (table 6; figure 8). Maintaining the no-layoff policy does keep commitment to TQM high in manufacturing, where in the base case the layoffs cause it to collapse. Nevertheless, the critical defect measures improve only slightly by 1991 compared to the base case. The main near term effect of the no-layoff policy is to keep ADI's costs from falling, reducing profit and the stock price further below base case levels.

The no-layoff policy does little in the short run because the primary problem is the excess 
capacity created by the successful defect reductions before the layoff, not the failure of defects to drop further after the layoff. After the layoff, TQM stalled, but by then the 'damage' - the excess capacity, under absorbed overhead, and reputation for poor cost control - was done. By the time of the layoff, ADI's stock price had already fallen, forcing management to focus on short-term financial pressures. Maintaining the no-layoff policy does nothing to prevent these financial pressures from arising in the first place; rather it intensifies them.

Indeed, despite the no-layoff policy, commitment to TQM in the manufacturing organization has fallen from nearly $100 \%$ in 1988 to under $60 \%$ by 1991 . Commitment falls partly because diminishing returns set in. Having harvested the low-hanging fruit in the first two years of TQM, further improvements become more difficult, reducing the perceived benefit of additional effort. Higher commitment created by the no-layoff policy also means there are more TQM efforts than in the base case. These efforts lead to additional frustration as more improvement teams seek support from their managers, undercutting commitment. Most important, however, the no layoff policy significantly intensifies the financial stresses facing ADI. With lower profitability and stock price, the ratio of market value to free cash flow falls below the already dangerous levels of the base case, intensifying the threat of a takeover. Even more of management's attention is diverted from TQM towards short-term financial fire-fighting. As management support for TQM falls, frustration rises, and TQM commitment falls.

The no-layoff policy ultimately outperforms the base case: by 1993 the policy yields higher quality, revenue, profits, and stock price, illustrating the 'worse-before-better' tradeoff between short and long term. However, the model does not include the possibility of shareholder revolt or hostile takeover, both more likely than in the base case because financial stresses are more intense in the short run - the company may not have survived as an independent entity long enough to enjoy the benefits of the no-layoff policy.

Thus job security is no guarantee of TQM success, and may be self-defeating. By preserving jobs in the short run, ADI's financial results worsen, increasing the pressure for layoffs and the likelihood of top management turnover or outright takeover. In the event of a takeover, the new management, faced with the need to cut costs, restore profitability, and pay down debt acquired to finance the acquisition, would almost certainly abandon the no-layoff policy. 


\subsection{Maintaining Morale While Downsizing}

The no-layoff case illustrates a strong tradeoff between short and long run effects, a tradeoff Analog might not have survived. To consider how the long-term benefits of employee security can be maintained while still making the necessary cost reductions, we now consider a policy of 'wise layoffs.' By wise layoffs we mean a policy in which job reductions are made without destroying commitment to TQM. Achieving this goal is clearly difficult in a weak economy. Nevertheless, a number of policies might be effective in reducing the negative effect of downsizing on workforce commitment and morale: (i) employees who are most successful in reducing defects and improving quality can be rewarded by keeping their jobs or transferring to areas where quality did not improve as rapidly, thus creating an incentive to improve more rapidly rather then less; (ii) TQM tools can be used to identify where cuts should be made, so that workers understand the rationale for and participate in the decision to cut jobs, thus increasing the perception of fairness among the workforce; (iii) management can seek to persuade the workforce that without quality improvement more (or all) jobs will be lost to competitors, thus offsetting the fear of TQM induced layoffs with a greater fear of business failure.

We test a perfect and costless policy in which layoffs have no effect on employee commitment to TQM (the function $\mathrm{f}_{s}\{s\}$ is set identically to zero). The policy not only means employee morale is completely unaffected by layoffs and financial stress, but that the time consuming and disruptive changes that accompany downsizing, including deciding where and how much to cut, providing outplacement services and support for redundant employees, reassigning the remaining employees, and rebuilding experience among new work groups, have no impact on TQM effort or managerial attention and resources for TQM. Such a perfect policy can never be accomplished in reality. Nevertheless, the policy provides a benchmark to assess the potential for policies that can reduce turmoil and low morale associated with downsizing.

Indeed, the 'wise layoff' policy mitigates the tradeoff (table 7; figure 8). Employment falls by about the same amount as in the base case, but because, by assumption, commitment to TQM remains high, there is further quality improvement, leading to higher operating profits by 1991. Higher profits lead to higher stock prices, reducing the threat of a takeover. By 1993 the policy produces large benefits, outperforming the no-layoff case. Without the short-term penal- 
ties caused by the no-layoff policy, the wise-layoff policy leads to even higher levels of commitment to TQM in both manufacturing and product development, and thus higher quality, revenues, profit, and share price. Note that because TQM has led to even greater improvement compared to the base case, simulated 1993 employment is $13 \%$ less than the base case despite a $13 \%$ increase in sales.

The results show large benefits accruing from efforts to maintain employee morale and moderate the disruption caused by downsizing and reorganization. However, even in the wise layoff case the company experiences severe financial stress. Despite the wise layoff policy, operating profit, share price, and market value relative to cash flow all fall substantially between 1989 and 1991, forcing Analog to lay off a significant number of employees. While human resource policies addressing employment security and morale speed Analog's recovery from the crisis, even perfect management of human resources does not prevent it.

\subsection{Maintaining Operating Margins}

Analog's dilemma arose from the rapid improvement they achieved in the manufacturing operation compared to the slow pace of improvement in activities that can generate new demand, including identifying new market opportunities, assessing customer needs, developing new products, and improving distribution channels. Progress was unbalanced because improvement halflives in most manufacturing operations are shorter than in activities such as product development, marketing, distribution, and management, due to their greater technical and organizational complexity. Further, management believed early results were needed to bootstrap commitment to $\mathrm{TQM}$, and allocated support resources preferentially towards those areas showing the most improvement. The preference for rapid results led to even faster progress in manufacturing and even less support for improvements in product development, sales, and administration.

Unbalanced improvement caused two critical side effects. First, excess capacity arose because capacity grew faster than demand. Second, direct costs per unit (driven by progress in manufacturing operations) fell faster than indirect costs per unit (driven by progress in $R \& D$, sales, administration and other overhead functions). Price-setting, however, sntinued to reflect the traditional cost structure, leading to a significant erosion of operating profit as indirect costs, 
though falling, became a larger share of unit costs.

Suppose Analog had understood the impact of differential improvement rates and adjusted its pricing policy to maintain profit margins as the cost structure changed. Table 5 shows that to maintain the 1985 ratio of operating income to sales (on a per unit basis), prices in 1989 should have been about 5\% higher than the historical 1989 value. We thus test a policy in which the target markup ratio rises 5\% between 1988 and 1989. Prices still fall, though more slowly, to compensate for the slower rate of improvement in indirect costs compared to direct costs.

The policy leads to superior performance (table 8, figure 9). As shown in table 8, the higher price policy has no effect on revenues in 1991 compared to the base case, but operating profits and share price rise by about $20 \%$. By 1993 the higher margin policy yields a small increase in revenue and boosts operating profit and the stock price by almost fifty percent compared to the base case.

Significantly, the higher margin policy is effective even though we assume the long-run elasticity of demand with respect to price is greater than unity. Several forces are responsible:

First, though the long-run price elasticity of demand is high, revenues don't drop in the short run because customers are locked in to existing contracts, and require time to redesign their own products to use competitor chips. The lock-in effect is modest, however, as we assume only a nine month lag in the adjustment of market share to changes in price.

Second, competitors respond to Analog's pricing. Competitors are assumed to pursue an aggressive price policy, pricing their own products at the lesser of a fraction of Analog's own price or the level that provides normal profits given their unit costs. Under the higher margin policy, Analog's prices fall more slowly, causing the competitors to lower their own prices more slowly as well, leaving relative attractiveness nearly unchanged. However, the effect of competitor accommodation is short-lived. By the middle of 1989 the competitors' own improvement efforts have reduced their costs enough for them to lower prices below the traditional ratio to Analog. After this point, competitors price as low as possible regardless of Analog's price.

Third, because higher margins improve revenues and operating profit, the share price does not fall as much as the base case. The improvement in financial results delays and reduces the magnitude of layoffs, leading to higher commitment to TQM and thus higher quality. By 
1991 the higher margin policy produces higher yield, lower defects and cycle time, and improved delivery performance compared to the base case. Thus even though higher prices make Analog's products less attractive, the other attributes of product attractiveness rise above base case levels, partially offsetting the effect of higher prices.

Fourth, the increase in revenue caused by higher margins leads to higher R\&D spending and thus a greater number of new products. As the number of new products grows, total demand increases, offsetting the reduction in market share caused by higher prices. Due to the long product development time the effect is a modest $1 \%$ increase in the number of breakthrough products on the market by 1991 . However, the effect is cumulative because of the positive feedback of higher sales, greater R\&D spending, more new products, and still higher sales. By 1993 the product portfolio has grown $2 \%$ larger than the base case. The impact on sales is even greater since the new products, in the early stages of their lifecycle, boost demand growth.

Fifth, higher demand increases capacity utilization compared to the base case. Higher utilization means unit costs fall below base case levels, since total costs are apportioned over a larger volume. Thus while the markup ratio rises by $5 \%$ under the policy, prices do not rise as much. By mid 1989, before the incremental new product development has had any impact, Analog's simulated price has risen 5\% compared to the base case. By 1993, greater quality and especially the introduction of additional new products boost volume and lower unit costs compared to the base case so that Analog's price rises only $2 \%$ above the base case. Thus the cumulative effects of higher margins on volume and quality feed back to reduce the price differential and improve Analog's competitiveness even as Analog maintains a higher profit margin.

The benefits of the higher margin policy illustrate the complexity of the feedback processes governing the dynamics Analog experienced. Since we assume demand is more than unit elastic, higher margins would reduce revenues and hurt the firm if all else remained constant. But because the higher margin policy leads to higher quality, additional product development, higher volumes, and lower unit costs, revenues and profitability increase.

The results of the higher margin policy are contingent on a variety of assumptions, particularly customer preferences and competitor behavior. Sensitivity analysis shows the benefits of the higher margin policy fall as the elasticity of product attractiveness to price increases, 
as the lag in the response of customers to price changes shortens, and as the competitors' ability to cut costs improves. We assume price is the most important attribute of attractiveness, with a price elasticity of attractiveness of -3 . Increasing the elasticity of product attractiveness with respect to price to -4 reduces the benefits of the policy, though it still dominates the base case. When the sensitivity of attractiveness to price rises to -5 , the higher margin policy has a net negative effect on Analog. On the other hand, to the extent competitors follow Analog's lead in pricing rather than aggressively cutting price as their own costs fall, the benefits of higher margins would be even greater. Likewise, the higher margin policy will be more beneficial to the extent Analog can speed new products to market, increase the quality of their products, or lock customers in to its own products by offering new products not yet cloned by the competition.

\section{Discussion}

Quality advocates argue that successful improvement programs lead to competitive advantage and superior financial results. Analog's TQM experience appears paradoxical because significant improvements in quality were followed by deterioration in financial results. The resolution of the paradox is the recognition that the link between successful improvement and financial results is much more complex. Improvement programs are tightly coupled with the other activities of the firm, along with its customers, competitors, and the financial markets.

A core result of the model is the unbalanced impact of improvement activity on different parts of the organization. Processes with low technical and organizational complexity will improve most rapidly. The processes with lowest complexity and the fastest improvement rates tend to be capacity augmenting, while demand-generating activities like new product development, customer needs assessment, and reorientation of product mix and distribution strategy have the highest complexity and the slowest improvement rates. The throughput of a machine on the factory floor can be improved quickly: the laws of physics governing the process are well understood; the improvement team consists of the operators and others from the plant; experiments can be designed and carried out rapidly; confounding variables can be kept to a minimum. In contrast, demand-generating activities such as learning to assess the voice of the customer, developing new products faster and more effectively, allocating resources among 
divisions, and forging customer alliances require the participation of top management along with people from multiple divisions, functions, disciplinary backgrounds, and other firms. The 'laws' governing these processes are much less obvious than the laws of physics, and the tools available to improve them less highly developed. It takes longer to design and carry out experiments, and during this time changes in the environment confound the interpretation of results. Thus improvement programs are likely to increase capacity faster than demand, and will lower unit production costs faster than unit indirect costs.

A simple calculation reveals how fast productivity can grow before creating excess capacity. The labor requirements of any firm are giv by sales divided by labor productivity. The fractional rate of change of labor requirements, $1^{*}$, is thus determined by the fractional growth in sales, $\mathrm{s}$, less the fractional rate of productivity growth, $\mathrm{p}$ :

$$
1^{*}=\mathrm{s}-\mathrm{p}
$$

Denoting the magnitude of the fractional attrition rate from the labor force as a, the maximum rate of productivity growth consistent with a no-layoff policy is thus:

$$
\mathrm{p} \leq \mathrm{s}+\mathrm{a}
$$

Thus the more successfully an organization improves its manufacturing operations, the more intense the tradeoff will be. From its founding through 1985, Analog's sales growth averaged $27 \%$ per year. Throughout much of this period the New England economy was booming, and turnover was high - a senior human resources manager estimated it to be $10-20 \%$ per year - as employees readily found new opportunities in the vigorous electronics industry. During the boom, productivity growth of 40 to $50 \%$ per year could have been accommodated by sales growth and normal attrition. However, as growth faltered and unemployment rose, voluntary quits shrank to less than $5 \%$ per year. With negligible attrition and sales growth less than $10 \% / y e a r$, even small rates of improvement necessarily led to excess employment.

The confluence of weak economy, low attrition, and TQM is not coincidental. Many companies implement quality programs in reaction to the competitive pressures caused by slow demand growth. A weak economy suppresses voluntary turnover. TQM has become popular in 
the US precisely when firms are least able to absorb productivity gains without layoffs.

The analysis above applies not just to TQM but to any improvement techniques, such as business process re-engineering, that depends for its success on the efforts or cooperation of the employees. The faster productivity rises - regardless of how the gains are achieved - the greater the risk of excess capacity. The dilemma has not received sufficient attention in the human resources literature. For example, Bluestone and Bluestone (1992) suggest firms create commitment to programs like TQM by guaranteeing job security if the workers can boost productivity by, they suggest, $6 \% /$ year. In mature industries, or industries suffering from the global recession where sales growth is substantially less than $6 \% /$ year, the productivity improvement can only be absorbed if attrition is high or if market share can be increased at the expense of competitors. Obviously, competitors will not accept such losses meekly, raising the specter of price cuts that can undermine profits and force the firm into downsizing.

At Analog the dilemma was acute. Analog's history of growth and employment security meant the first layoff would have enormous symbolic impact. Yet in a stagnant economy there would be strong pressure for layoffs if TQM improved manufacturing before faster and better product development could build new markets. The other horn of the dilemma was equally sharp. Analog could not afford to delay implementing TQM. Analog's customers were demanding higher performance from their suppliers, and competition was intensifying. As the simulations show, failure to improve would have threatened Analog's industry leadership and, perhaps, its very survival.

Analog faced a strong tradeoff between the short and long run impacts of TQM.

Maintaining commitment to TQM by guaranteeing job security does benefit the firm in the long run as higher commitment leads to higher quality and greater success in the marketplace. However, maintaining employment worsens the already severe financial stress Analog experienced. Analog's vulnerability to hostile takeover would have increased. But in the long run, financial results are superior, downsizing pressures subside and commitment to continuous improvement is higher. To the extent management can work with the employees to reduce the fear of job losses the tradeoff can be mitigated.

The interaction of TQM with pricing policy compounded Analog's difficulties. Given 
the traditional markup, the faster manufacturing improved, the greater the disparity between direct and indirect costs, and the larger the resulting reduction in profits. Lower profits then feed back to intensify the need for layoffs, divert managerial attention from TQM to financial firefighting, and trigger the collapse of commitment to TQM, with resulting backsliding of quality, loss of market share, and pressure to cut prices further.

The core of the dilemma is the belief that people will not participate in new programs like TQM unless they can see the benefits right away. On the one hand, academics and practitioners assert that "successful change programs begin with results" (Schaffer and Thomson 1990). Early results are widely advocated to overcome the "prove it to me" attitude by demonstrating the validity of the program, kick-start diffusion and boost the virtuous cycle of commitment and effort (Shiba, Walden and Graham 1993). On the other hand, a focus on quick results biases decisions against innovations with long time delays and leads to myopic resource allocation. The side effects of such policies may feed back to undermine the program in the long term. Areas where improvement is fastest tend to augment capacity. Demand-generating activities such as product development and customer partnerships are intrinsically complex and can not yield results as quickly. A focus on early results may lead to excess capacity, financial stress, downsizing, low morale, and the collapse of commitment to the program. Improvement programs can fail not in spite, but precisely because of their early success.

\section{Implications and further research}

TQM represents a significant advance in tools for organizational learning and improvement. The success of TQM in improving operations stems from the focus on continuous improvement and workforce participation. These are formidable benefits. Yet TQM is also limited. Specifically, TQM relies on tools and processes that assume the separability of causes in the system under study. TQM as currently practiced assumes a quality improvement team can rank the causes of defects for a given process and address them sequentially. TQM tools such as Pareto charts and Ishikawa diagrams produce lists of causes of different defects. ${ }^{11}$ Efforts to improve different processes often progress independently of one another - a plant might have dozens of different improvement teams operating simultaneously. TQM grows out of the belief 
that the world can be decomposed into independent causes generating independent effects.

Decomposition is a time-honored problem solving strategy (Simon 1969). It often works effectively, provided the process under consideration is not strongly coupled to other systems in the environment. When couplings are strong, however, decomposition may lead to ineffective policies. Worse, piecemeal policies may intensify the problem (Forrester 1971, Meadows 1982, Ackoff 1978, 1981), or even lead to catastrophe (Perrow 1984). Decomposition methods ignore feedback processes and interactions, and discount time delays and side effects. Decomposition in complex, tightly coupled dynamic systems optimizes the parts at the expense of the whole and the present at the expense of the future.

While many couplings on the factory floor, where TQM evolved, are weak, couplings at the upper management level are strong. Customer needs assessment, product development, strategic planning, organization design, and resource allocation involve high technical and organizational complexity. For example, a product development team is tightly coupled with other functions within the firm (process engineering, marketing, finance, etc.) and with many organizations outside the firm (customers, vendors, competitors, etc.). Experiments to evaluate different ways to translate customer requirements into product specifications take months to carry out, and face many confounding variables (see Burchill 1993 for a compelling example). Available TQM tools can not lead to rapid improvement when couplings are tight, time delays are long, and feedback is ambiguous. Tools and processes to help redesign complex activities like product development are less mature than the TQM methods that proved so effective on the factory floor. Stata commented "The thing that hung us up for the longest time in the product development [PD] area is that we didn't have anybody in the company who had a clue as to how to improve PD. It wasn't that we didn't think it was important, but how do you do it?"

The next generation of TQM tools should incorporate an explicit feedback view of the firm and its environment. The tools should help managers understand the long-term, organization-wide consequences of their actions. Since ADI's initial efforts, several techniques have been proposed to address these problems. These include concept engineering (Burchill 1993), quality function deployment (Hauser and Clausing 1988), Hoshin planning (Shiba, Walden and Graham 1993), soft systems methods such as cognitive mapping (Checkland 1981, Eden, Jones, 
and Sims 1983, Wolstenholme 1990), and simulation and gaming (Carroll, Marcus and Sterman 1993, de Geus 1988, Morecroft 1988, Morecroft and Sterman 1992, Senge and Sterman 1991). Further research and field tests are needed to assess the effectiveness of these tools.

Analog had all the information needed to anticipate the dynamics of TQM described here. Their own data suggested improvement half-lives of less than a year in capacity-augmenting activities like yield, defects and cycle time and longer than three years in demand-generating activities like product development (recall figure 1 and table 1). While uncertainties would obviously be greater ex ante, the results depend on fundamental structural features that are not in doubt: manufacturing improves faster than product development; direct costs fall faster than indirect costs; success generates enthusiasm and leads to further effort; competitors do not stand still. What Analog lacked was a framework enabling them to understand the implications of their knowledge. Stata reflected "We didn't have a deep enough appreciation for the complexity we faced in our systems. Typical managers today are just not skilled at that, even high up." 


\section{Notes}

1 A more detailed description of Analog and its TQM experience is found in Kaplan 1990a and 1990b.

2 The half-life satisfies $.5\left(D_{t_{0}}-D_{\min }\right) /\left(D_{t_{0}}-D_{\min }\right)=\exp \left(-\phi t_{h}\right)$.

3 The scorecard evolved over time as better metrics were identified.

4 Schneiderman left Analog at the end of 1992 and became an independent consultant.

5 The model is a large system of coupled nonlinear differential equations. Complete documentation is available from the authors.

6 The economic growth index was not significant, apparently because the variance in annual demand growth is not great enough to estimate the relationship. Alternatively the index of electronic components may be too crude a proxy of demand. Nevertheless, since the macroeconomy must influence the demand for ADI's products, we retain $\mathrm{g}^{\mathrm{e}}$ in the model with an income elasticity of unity, which is not significantly different from the estimated value.

7 In 1991 ADI acquired one of its competitors, PMI. The acquisition is not incorporated in the model, so comparisons after 1991 are not meaningful.

8 Actually these activities took time and were distributed over a several month period. The assumed starting time represents a good midpoint for the startup process.

9 In reality the strength of the sole-source effect is mediated by quality. When quality is low, customers will be reluctant to depend on a small number of suppliers. When delivery reliability and quality are high, however, customers may prefer to reduce the number of suppliers. Many TQM advocates call for vendor partnering to involve suppliers in the improvement process.

10 It might be argued that the decline in prices was due entirely to market pressures outside of Analog's control. If so, the drop in profits was not a side effect of TQM but the inevitable result of increased competition. Clearly competition has intensified. Historically few substitutes wcre available for Analog's mostly proprietary products. Beginning in the mid 1980s, competitors began to produce 'pin compatible' substitutes offering identical functionality. ADI's business also began to shift away from defense-related applications towards markets such as consumer electronics where competition is more intense and margins are lower. If ADI used markup pricing exclusively and ignored competitive pressures entirely, the $15.8 \%$ decline in unit production costs from 1985 to 1989 would yield the same fractional reduction in average selling prices. Average selling prices actually fell $17.2 \%$, an additional drop of 1.4 percentage points, implying intensifying competition and shifting product mix caused prices to fall $9 \%$ beyond the decline in unit costs. If average prices had fallen only as much as unit costs, operating income per unit would still have fallen $35 \%$ because of the smaller drop in indirect costs per unit.

11 More sophisticated tools for improvement such as Taguchi and other experimental design techniques can accommodate nonlinearities and interactions. However, we are not aware of any applications of these design methods to managerial processes. 


\section{References}

(1992) The Cracks in Quality. The Economist. 322, 67.

Abdel-Hamid, T. and S. Madnick (1991) Software Project Dynamics: An Integrated Approach. Englewood Cliffs, NJ: Prentice Hall.

Ackoff, R. (1981) Creating the Corporate Future. New York: John Wiley and Sons.

Ackoff, R. (1978) The Art of Problem Solving. New York: John Wiley and Sons.

Analog Devices (1991). TQM at ADI. Norwood, MA: Analog Devices.

Appelbaum, E. \& R. Batt (1994) The New American Workplace: Transforming work systems in the United States. Ithaca, NY: ILR Press

Balz, W. and S. Garberding (1993) A system dynamics analysis of total quality management implementation issues. Unpublished MS thesis, Sloan School of Management, MIT.

Barlas, Y. (1989). Multiple Tests for Validation of System Dynamics Type of Simulation Models. European Journal of Operations Research, 42(1), 59-87.

Beaumont, P., L. Hunter, R. Phayre (1993) Human Resources and Total Quality Management: Some Case Study Evidence, Paper presented at the Canadian Industrial Relations Association Meetings, Ottawa, 3-5 June 1993.

Beer, M, B. Spector, and R. Eisenstadt (1990) Why change programs don't produce change. Harvard Business Review, Nov/Dec, 158-166.

Bluestone, B. and I. Bluestone (1992). Workers (and Managers) of the World Unite. Technology Review. November/December, 30-40.

Brown, J. and S. Tse (1992). A System Dynamics Analysis of Total Quality Management Implementation False Starts. Unpublished MS Thesis, Sloan School of Management, MIT.

Burchill, G. (1993). Concept Engineering: An investigation of TIME vs. MARKET orientation in product concept development. Unpublished Ph.D. Thesis, Sloan School of Management, MIT.

Carroll, J. S., Sterman, J. D., \& Marcus, A. A. (1993, Forthcoming). Losing the Maintenance Game: How Mental Models Drive Organizational Decisions. In Stern, R. \& Halpern, J. (Eds.), Nonrational Elements of Organizational Decision Making Ithaca, NY: ILR Press.

Checkland, P. (1981), Systems Thinking, Systems Practice, Wiley: Chichester.

Cyert, R. and March, J. (1963) A Behavioral Theory of the Firm. Englewood Cliffs, NJ: Prentice Hall.

de Geus, A.P. (1988) Planning as learning, Harvard Business Review, March-April, 70-74.

Deming, W. E. (1986) Out of the Crisis. Cambridge: MIT Center for Advanced Engineering Study.

Eden, C., Jones, S., \& Sims, D. (1983), Messing About in Problems, Oxford: Pergamon Press. 
Ehrler, S. and E. Jansen (1993). System Dynamics as an organizational diagnostic for total quality management implementation. Unpublished MS thesis, Sloan School of Management, MIT.

Ernst and Young (1991). "International Quality Study - Top Line Findings" and "International Quality Study - Best Practices Report” Ernst and Young/American Quality Foundation.

Feigenbaum, A. V. (1983) Total Quality Control. New York: McGraw Hill.

Forrester, J. (1961). Industrial Dynamics. Cambridge: The MIT Press.

Forrester, J. W. (1971). Counterintuitive Behavior of Social Systems. Technology Review. 73(3), $52-68$.

Forrester, J. W., \& Senge, P. M. (1980). Tests for Building Confidence in System Dynamics Models. In Legasto, A. et al. (Eds.), System Dynamics (209-228). New York: North-Holland.

Fuchsberg, G. (1993). Baldrige Awards may be losing their luster. Wall Street Journal. 19 April, B1.

Garvin, D. A. (1988) Managing Quality. New York: The Free Press.

General Accounting Office (1991). US companies improve performance through quality efforts. GAO/NSIAD-9-190 (2 May).

Gort, M. and S. Klepper (1982) Time paths in the diffusion of product innovations. Economic Journal 92, 630-653.

Hall, R. I. (1976). A System Pathology of an Organization: The Rise and Fall of the Old Saturday Evening Post. Administrative Science Quarterly, 21(2), 185-211.

Hall, R. I. (1983). A Corporate System Model of a Sports Club: Using Simulation as an Aid to Policy making in A Crisis, Management Science. 29(1), 52-64.

Hall, R. I. (1984) The Natural Logic of Management Policy Making: Its Implications for the Survival of an Organization. Management Science. 30, 905-927.

Harte, S. (1992) Corporate Style. Atlanta Journal \& Constitution. 11 October, R1.

Hauser, J. and D. Clausing (1988) The House of Quality. Harvard Business Review. 66(3), 63-73.

Homer, J. B. (1983). Partial-Model Testing As A Validation Tool for System Dynamics. In Proc. of the 1983 International System Dynamics Conference. Chestnut Hill, MA. 920-932

Ishikawa, K. (1985) What is Total Quality Control? Englewood Cliffs, NJ: Prentice Hall.

Jacob, R. (1993) TQM: More than a dying fad? Fortune. 18 October, 66-72.

Juran, J. M. (1988) Juran on Planning for Quality. New York: The Free Press.

Kaufman, R. (1992) Why Operations Improvement Programs Fail: Four Managerial Contradictions, Sloan Management Review, Fall, 83-93.

Kaplan, R. (1990a) Analog Devices: The Half-Life System, Case 9-191-061, Harvard Business School. 
Kaplan, R. (1990b) Analog Devices: The Half-Life System, Teaching Note 5-191-103, Harvard Business School.

Kaplan, R. and D. Norton (1992) The Balanced Scorecard - Measures that Drive Performance, Harvard Business Review, Jan-Feb. 1992, 71-79.

Kim, D. (1993). A framework and methodology for linking individual and organizational learning: applications in TQM and product development. Unpublished Ph.D. thesis, MIT Sloan School of Management, Cambridge, MA 02142.

Kim. D. and G. Burchill (1992) System Archetypes as a Diagnostic Tool: A Field Based Study of TQM Implementation. Proceedings of the 1992 International System Dynamics Conference. Utrecht: University of Utrecht, 311-320.

Kochan, T., H. Katz, R. McKersie (1986) The Transformation of American Industrial Relations. New York: Basic Books.

Lant, T. (1992) Aspiration Level Adaptation: An Empirical Exploration. Management Science. 38(5), 623-644.

Lawler, E., S. Mohrman, G. Ledford (1992). Employee Involvement and Total Quality Management. San Francisco: Jossey-Bass.

Lyneis, J. M. (1980) Corporate Planning and Policy Design. Portland, OR: Productivity Press.

Meadows, D. H. (1982) Whole Earth Models \& Systems, The CoEvolution Quarterly, Summer , 20-30.

Morecroft, J. (1985) Rationality in the Analysis of Behavioral Simulation Models. Management Science 31 (7): 900-916.

Morecroft, J. (1988) System dynamics and microworlds for policymakers, European Journal of Operational Research, 35, 301-320.

Morecroft, J. D. W., \& Sterman, J. D. (Eds.). (1992). Modelling for Learning: Special Issue of the European Journal of Operational Research. 59 (1), May.

Newman, G. (1991). The case against quality. Across the Board (The Conference Board). June, 58.

Paich, M. and Sterman, J. (1993) Boom, Bust, and Failures to Learn in Experimental Markets. Management Science, 39(12), 1439-1458.

Peterson, J. and L. T. How (1993). A system analysis of total quality management implementation false starts. Unpublished MS thesis, Sloan School of Management, MIT.

Perrow, C. (1984) Normal Accidents. New York: Basic Books.

Richardson, G. P. (1991). Feedback Thought in Social Science and Systems Theory. Philadelphia: University of Pennsylvania Press.

Roberts, E. B. (ed.). (1978) Managerial Applications of System Dynamics. Cambridge MA: Productivity Press.

Schaffer, R. and H. Thomson (1992) Successful Change Programs Begin with Results, Harvard Business Review, Jan/Feb. 80-89. 
Schmidt, P. (1992) TQM, Systems Thinking, and Organizational Learning: Is there a Missing Link? Unpublished MS Thesis, Sloan School of Management, MIT.

Schneiderman, A. (1988) Setting Quality Goals, Quality Progress. April, 55-57.

Schneiderman, A. (1991) A Model for TQM Problem Solving, Unpublished presentation.

Senge, P., \& Sterman, J. D. (1991). Systems Thinking and Organizational Learning: Acting Locally and Thinking Globally in the Organization of the Future. In Kochan, T. \& Useem, M. (Eds.), Transforming Organizations. Oxford: Oxford University Press, 353-370.

Shewhart, W. (1939) Statistical Method from the viewpoint of quality control. Washington, DC: US Department of Agriculture.

Shiba, S, D. Walden, A. Graham (1993) A New American TQM. Four Practical Revolutions in Management. Portland, OR: Productivity Press.

Simon, H. (1969) The Sciences of the Artificial. Cambridge, MA: MIT Press.

Stata, R. (1989) Organizational Learning - The Key to Management Innovation, Sloan Management Review, 30(3) Spring, 63-74.

Sterman, J. D. (1989a) Misperceptions of Feedback in Dynamic Decision Making. Organizational Behavior and Human Decision Processes 43 (3): 301-335.

Sterman, J. D. (1989b) Modeling Managerial Behavior: Misperceptions of Feedback in a Dynamic Decision Making Experiment. Management Science 35 (3): 321-339.

Sterman, J. D. (1984). Appropriate Summary Statistics for Evaluating the Historical Fit of System Dynamics Models. Dynamica, 10(2), 51-66.

Taylor, P. (1992). Such an Elusive Quality. Financial Times. 14 February, 9.

Theil, H. (1966) Applied Econometric Forecasting. Amsterdam: North Holland.

Value Line (1991a). Investment Survey: Supplementary Reports. 30 August, 1740.

Value Line (1991b) Investment Survey: Analog Devices, 1 November.

Value Line (1992) Investment Survey: Analog Devices, 1 May.

Walden, D. and T. Lee (1992). What is the Center for Quality Management? The Center for Quality Management Journal. 1(1), 3-8.

Walton, M. (1986) The Deming Management Method. New York: Dodd, Mead \& Co.

Wolstenholme, E. F. 1990. System Enquiry - A System Dynamics Approach. Chichester: John Wiley. 
Table 1. Analog Devices' Actual and Target Quality Measures, 1987 (Stata 1989)

1987

(actual)

$85 \%$

500 PPM

10 weeks

Internal Measures

Manufacturing cycle time

Process Defect Level

Yield

New Product Time to market

\section{External Measures}

Outgoing defect level

Delivery Lead time

15 weeks

5000 PPM

$20 \%$

36 months
Half-life

(months)
1992

(target)
$9 \quad>99.8 \%$

9

9

$<10$ PPM

$<3$ weeks

9 4-5 weeks

$6<10$ PPM

$9>50 \%$

246 months 
Table 2. The balanced scorecard (adapted from version in Kaplan 1990a).

Division

\begin{tabular}{|c|c|c|c|c|c|}
\hline & $\begin{array}{l}\text { Q1 } \\
\text { Plan }\end{array}$ & $\begin{array}{l}\text { Q1 } \\
\text { Actual }\end{array}$ & $\begin{array}{l}\text { Q 2 } \\
\text { Plan }\end{array}$ & $\begin{array}{l}\text { Q 2 } \\
\text { Actual }\end{array}$ & $\ldots$ \\
\hline $\begin{array}{l}\text { Financial } \\
\quad \text { Revenue } \\
\text { Revenue Growth } \\
\text { Profit } \\
\text { ROA }\end{array}$ & & & & & \\
\hline $\begin{array}{l}\text { QIP } \\
\text { On Time Delivery } \\
\% \text { CRDs not Matched } \\
\text { Excess Leadtime } \\
\text { Labor Turnover }\end{array}$ & & & & & \\
\hline $\begin{array}{l}\text { Manufacturing Metrics } \\
\text { Outgoing Defects (PPM) } \\
\text { Process Defects (PPM) } \\
\text { Cycle Time } \\
\text { Yield }\end{array}$ & & & & & \\
\hline $\begin{array}{l}\text { New Products } \\
\text { Bookings } \\
\text { New Product Introductions } \\
\text { Product Development Time }\end{array}$ & & & & & \\
\hline
\end{tabular}

Note: QIP = Quality Improvement Processes; CRD = Customer Requested Delivery Dates. 
Table 3 Model boundary, highlighting the main endogenous variables.

Endogenous

Physical:

Orders

Shipments

Production

Wafer Starts

Finished inventory

WIP

Materials Inventory

Capital stock

Labor force

Development engineers

Financial

Sales

COGS

Gross profit

Operating expense

$R \& D, G S A$ expenses

Depreciation

Operating income

Net income

Share price

\section{Managerial Accounting}

Labor, capital, \& materials, efficiency and volume variances

Overhead, $\mathrm{OH}$ burden rate

Overhead absorption variances

\section{Quality Metrics}

Semiconductor yield

Defective products shipped (PPM)

Delivery Time

On time delivery percentage

Manufacturing cycle time

Product development time

New product introduction rate

\section{Motivational variables}

Management commitment to TQM

Workforce commitment to TQM

Workforce perception of job security

TQM support resources

Managerial attention to TQM

Financial stress (pressure for layoffs)

Fraction of support to $\mathrm{mfg}$. vs. product development

Industry and Competitive Variables

Competitor price, quality measures

Analog price

Industry demand

Analog market share
Exogenous

Industrial Production Index for Electronic Components

Return on the Standard \& Poor's 500 (stock market yield)

Index of industry best practice for TQM

Wage and Price deflators

\section{Excluded}

Acquisitions

Patent expiration

Financing strategy

Massachusetts economy (e.g. labor attrition rates)

Changing customer mix (e.g. less dependence on gov't contracts) 
Table 4 Historical fit of model, 1985 - 1991.

Theil Inequality Statistics

\begin{tabular}{|c|c|c|c|c|c|c|}
\hline Variable & MAPE & Bias & $\begin{array}{l}\text { Unequal } \\
\text { Variation }\end{array}$ & $\begin{array}{l}\text { Unequal } \\
\text { Covariation }\end{array}$ & $R^{2}$ & $N$ \\
\hline Unit Sales & .04 & .03 & .02 & .95 & .95 & 6 \\
\hline Sales Revenue & .03 & .00 & .05 & .94 & .92 & 24 \\
\hline Cost of Goods Sold & .05 & .06 & .08 & .86 & .91 & 24 \\
\hline Operating Income & .22 & .04 & .34 & .61 & .69 & 24 \\
\hline$R \& D$ Budget & .07 & .09 & .01 & .90 & .89 & 24 \\
\hline Cum. Products Introduced & .04 & .00 & .53 & .47 & .99 & 24 \\
\hline Manufacturing Yield & .10 & .17 & .00 & .82 & .79 & 72 \\
\hline Outgoing Defects & .20 & .03 & .02 & .95 & .93 & 24 \\
\hline Mfg. Cycle Time & .11 & .10 & .03 & .87 & .86 & 24 \\
\hline On Time Delivery & .05 & .30 & .06 & .64 & .77 & 24 \\
\hline Market Value/Cash Flow & .17 & .00 & .15 & .85 & .79 & 6 \\
\hline Share Price. & .12 & .10 & .04 & .86 & .81 & 24 \\
\hline
\end{tabular}

Note: MAPE $=$ Mean Absolute Percent Error between simulated and actual variables. Bias, Unequal Variation, and Unequal Covariation are the Theil Inequality Statistics showing what fraction of the mean square error between simulated and actual series is due to unequal means, unequal variances, and imperfect correlation, respectively. Low bias and unequal variation fractions indicate the error is unsystematic. $\mathrm{N}$ is the number of data points in the historical series. Theil statistics may not add to 1.00 due to rounding. 
Table 5. Changes in cost structure caused by TQM interacted with pricing policy to yield lower profit.

\begin{tabular}{lrrr}
\multicolumn{4}{c}{ Historical Data } \\
& & & \\
\$/unit & 1985 & 1989 & $\% \Delta$ \\
Ave. Selling Price & 16.32 & 13.51 & -17.2 \\
- Cost of Goods Sold & 7.61 & 6.41 & -15.8 \\
$=$ Gross Profit & 8.71 & 7.10 & -18.5 \\
$=$ - Indirect Costs & 6.35 & 5.80 & -8.7 \\
\hline Operating Income & 2.36 & 1.30 & -44.7 \\
& & & \\
& & & \\
$=$ & & & \\
& Markup Ratio (\%) & & \\
\end{tabular}

All figures expressed per unit sold. $\% \Delta$ column shows the change as a percent of the 1985 value.

Source: Sales Revenue, COGS (Cost of Goods Sold), and Operating Expense Data from 1987 and 1989

Annual Reports. Unit Sales Data provided by ADI. Indirect costs include General, Sales, Marketing,

$R \& D$, and Administrative expenses. 
Table 6. Policy Analysis: No-Layoff policy vs. Base Case.

\begin{tabular}{|c|c|c|c|c|c|c|}
\hline \multirow[b]{2}{*}{ Variable } & \multicolumn{3}{|c|}{1991} & \multicolumn{3}{|c|}{1993} \\
\hline & Base Case & No-Layoff & $\% \Delta$ & Base Case & -Layoff & $\% \Delta$ \\
\hline Revenue ( $\$$ Million/qtr) & 111 & 113 & 2 & 121 & 133 & 10 \\
\hline Operating Income ( $\$$ Million/qtr) & 5.7 & 5.0 & -12 & 8.0 & 10.7 & 34 \\
\hline R \& D Expenditure ( $\$$ Million/qtr) & 17.4 & 17.6 & 1 & 18.2 & 19.6 & 8 \\
\hline Work Force in Mfg (people) & 1434 & 2231 & 56 & 1369 & 1871 & 37 \\
\hline Comm to TQM in Mfg (dimensionless) & 0.01 & 0.57 & $0.56^{*}$ & 0.34 & 0.79 & $0.45 *$ \\
\hline Comm to TQM in PD (dimensionless) & 0.37 & 0.25 & $-0.12 *$ & 0.88 & 0.72 & -0.16 \\
\hline Breatkthrough Products on the Market & 284 & 283 & 0 & 331 & 335 & 1 \\
\hline Manufacturing Yield $(\%)$ & 0.40 & 0.42 & 5 & 0.37 & 0.44 & 19 \\
\hline Outgoing Defects (PPM) & 268 & 195 & -27 & 399 & 190 & -52 \\
\hline Mfg Cycle Time (months) & 2.17 & 1.94 & -11 & 2.57 & 1.94 & -25 \\
\hline OTD (dimensionless) & 0.93 & 0.96 & 3 & 0.89 & 0.96 & 8 \\
\hline Product Dev. Time (months) & 25.4 & 25.5 & 1 & 22.7 & 23.1 & 2 \\
\hline Stock Price ( $\$ /$ share) & 8.22 & 7.50 & -9 & 11.88 & 14.67 & 23 \\
\hline
\end{tabular}

* The values in the ' $\% \Delta$ ' column for Commitment to TQM in Manufacturing and Product development are absolute differences. 
Table 7. Policy Analysis: Wise Layoffs vs. Base Case.

1991

Variable

Revenue (\$ Million/qtr)

Operating Income (\$ Million/qtr)

$R$ \& D Expenditure (\$ Million/qtr)

Work Force in $\mathrm{Mfg}$ (people)

Comm to TQM in Mfg (dimensionless)

Comm to TQM in PD (dimensionless)

Breatkthrough Products on the Market

Manufacturing Yield (\%)

Outgoing Defects (PPM)

Mfg Cycle Time (months)

OTD (dimensionless)

Product Dev. Time (months)

Stock Price (\$/share)

Base Case Wise Layoffs $\% \Delta$ Base Case Wise Layoffs $\% \Delta$

$\begin{array}{rrrrrr}111 & 113 & 2 & 121 & 137 & 13 \\ 5.7 & 7.3 & 28 & 8.0 & 13.8 & 73 \\ 17.4 & 17.5 & 1 & 18.2 & 20 & 10 \\ 1434 & 1437 & 0 & 1369 & 1197 & -13 \\ 0.01 & 0.61 & 0.60^{*} & 0.34 & 0.89 & 0.55 * \\ 0.37 & 0.30 & -0.07 * & 0.88 & 0.84 & -0.04 * \\ 284 & 285 & 0 & 331 & 337 & 2 \\ 0.40 & 0.42 & 5 & 0.37 & 0.45 & 22 \\ 268 & 193 & -28 & 399 & 177 & -56 \\ 2.17 & 1.96 & -10 & 2.57 & 1.88 & -27 \\ 0.93 & 0.96 & 3 & 0.89 & 0.96 & 8 \\ 25.4 & 25.5 & 1 & 22.7 & 22.3 & -2 \\ 8.22 & 9.25 & 13 & 11.88 & 20.52 & 73\end{array}$

* The values in the ' $\% \Delta$ ' column for Commitment to TQM in Manufacturing and Product development are absolute differences.

For the Wise Layoff policy the function $f_{s}\{s\}$ is set identically to zero (see eq. 10), so that layoffs have no impact on commitment to TQM. 
Table 8. Policy Analysis: $5 \%$ Increase in target margin phased in from 1988-1989.

\begin{tabular}{lrrrrrrr} 
& \multicolumn{3}{c}{1991} & & \multicolumn{3}{c}{1993} \\
Variable & Base Case & $+5 \%$ Margin & $\% \Delta$ & Base Case & $+5 \%$ Margin & $\% \Delta$ \\
& & & & & & & \\
& & & & & & \\
Revenue (\$ Million/qtr) & 111 & 111 & 0 & 121 & 124 & 2 \\
Operating Income (\$ Million/qtr) & 5.7 & 6.9 & 21 & 8.0 & 11.4 & 43 \\
R \& D Expenditure (\$ Million/qtr) & 17.4 & 17.5 & 1 & 18.2 & 18.5 & 2 \\
Work Force in Mfg (people) & 1434 & 1428 & 0 & 1369 & 1303 & -5 \\
Comm to TQM in Mfg (dimensionless) & 0.01 & 0.02 & $0.01 *$ & 0.34 & 0.48 & $0.14^{*}$ \\
Comm to TQM in PD (dimensionless) & 0.37 & 0.35 & $-0.02 *$ & 0.88 & 0.91 & $0.03 *$ \\
Breatkthrough Products on the Market & 284 & 287 & 1 & 331 & 336 & 2 \\
Manufacturing Yield (\%) & 0.40 & 0.41 & 2 & 0.37 & 0.39 & 5 \\
Outgoing Defects (PPM) & 268 & 246 & -8 & 399 & 340 & -15 \\
Mfg Cycle Time (months) & 2.17 & 2.10 & -3 & 2.57 & 2.42 & -6 \\
OTD (dimensionless) & 0.93 & 0.94 & 1 & 0.89 & 0.92 & 3 \\
Product Dev. Time (months) & 25.4 & 25.3 & 0 & 22.7 & 22.3 & -2 \\
Stock Price (\$/share) & 8.22 & 9.76 & 19 & 11.88 & 17.65 & 49
\end{tabular}

* The values in the ' $\% \Delta$ ' column for Commitment to TQM in Manufacturing and Product development are absolute differences. 
Figure 1. Dependence of improvement half lives on technical and organizational complexity. Adapted from Schneiderman (1991).
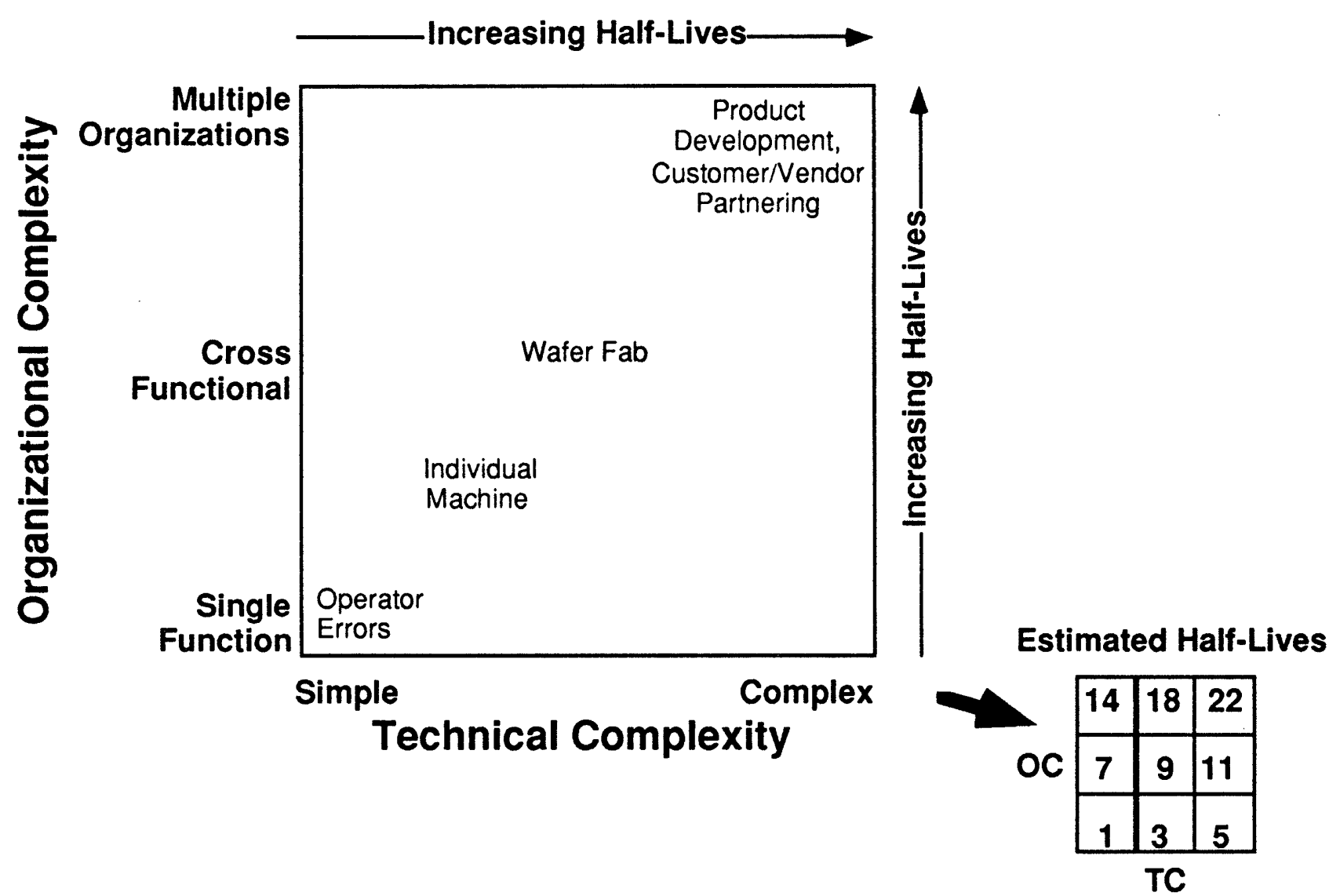
Figure 2. Overview of Model Structure

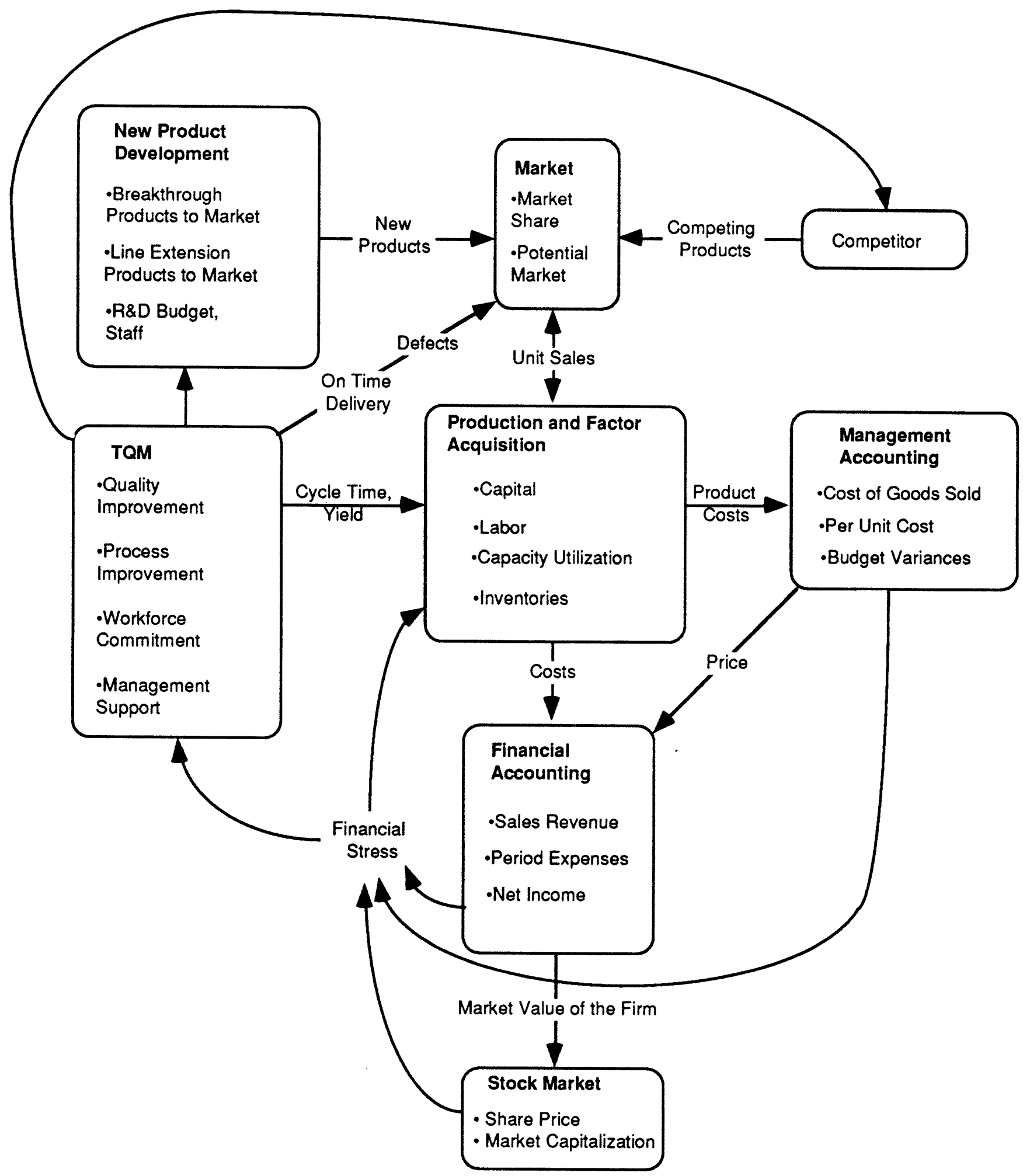


Figure 3. Dependence of Sales Growth on Product Age.

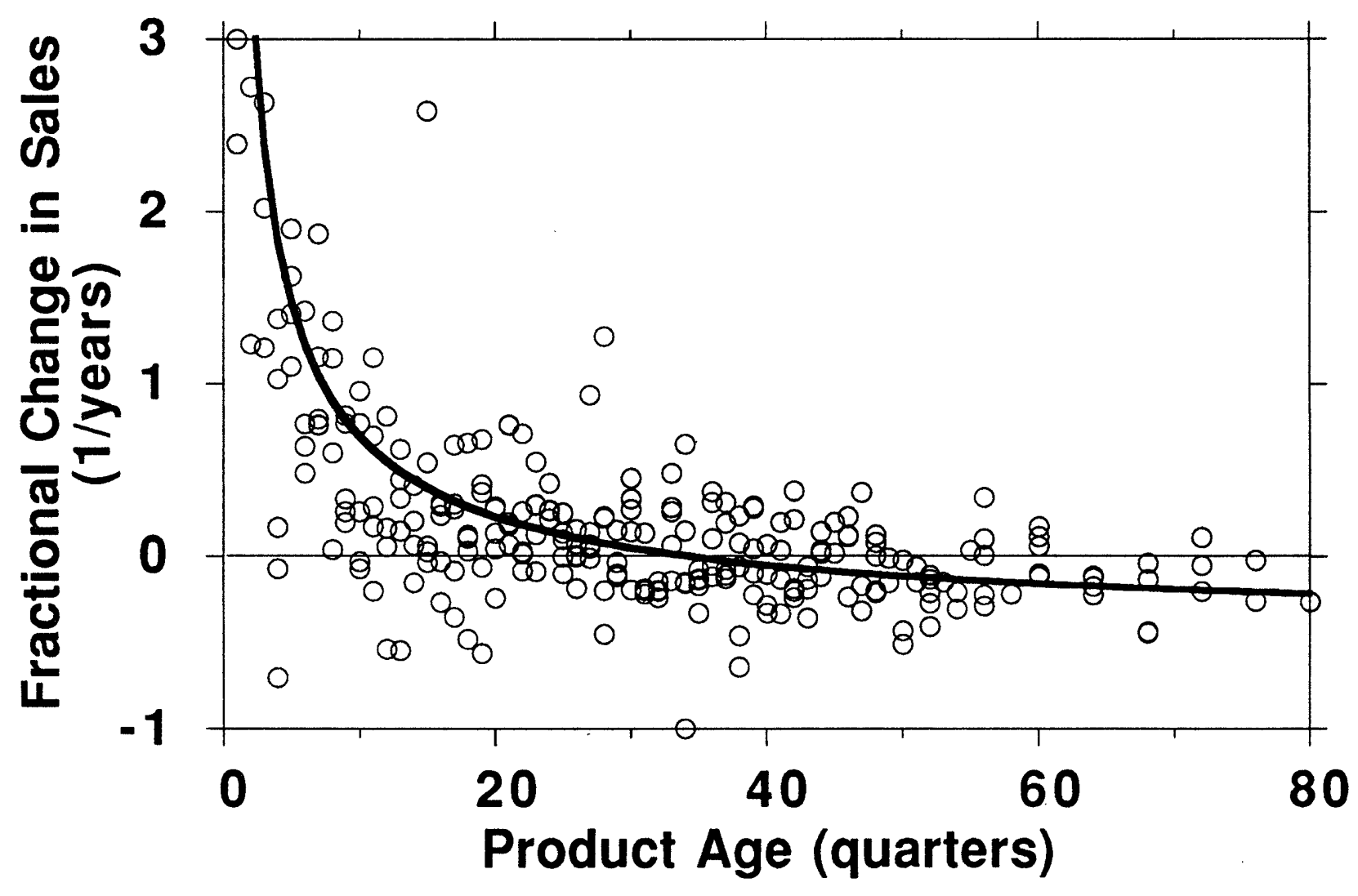

Model: $g_{i, A, t}=\alpha+\beta\left(A_{i, t}\right) \gamma+\delta g e_{t}+\varepsilon_{t}$

$\begin{array}{ccc}\text { Parameter } & \text { Estimated Coefficient } & \text { Asymptotic Standard. Error } \\ \alpha & -.465 & .178 \\ \beta & 6.413 & .407 \\ \gamma & -.743 & .088 \\ \delta & .052 & .914 \\ \overline{\mathrm{R}}^{2}=.51, \mathrm{~N}=270 . & & \end{array}$


Figure 4. Comparison of simulated and actual data: Sales and Financial metrics
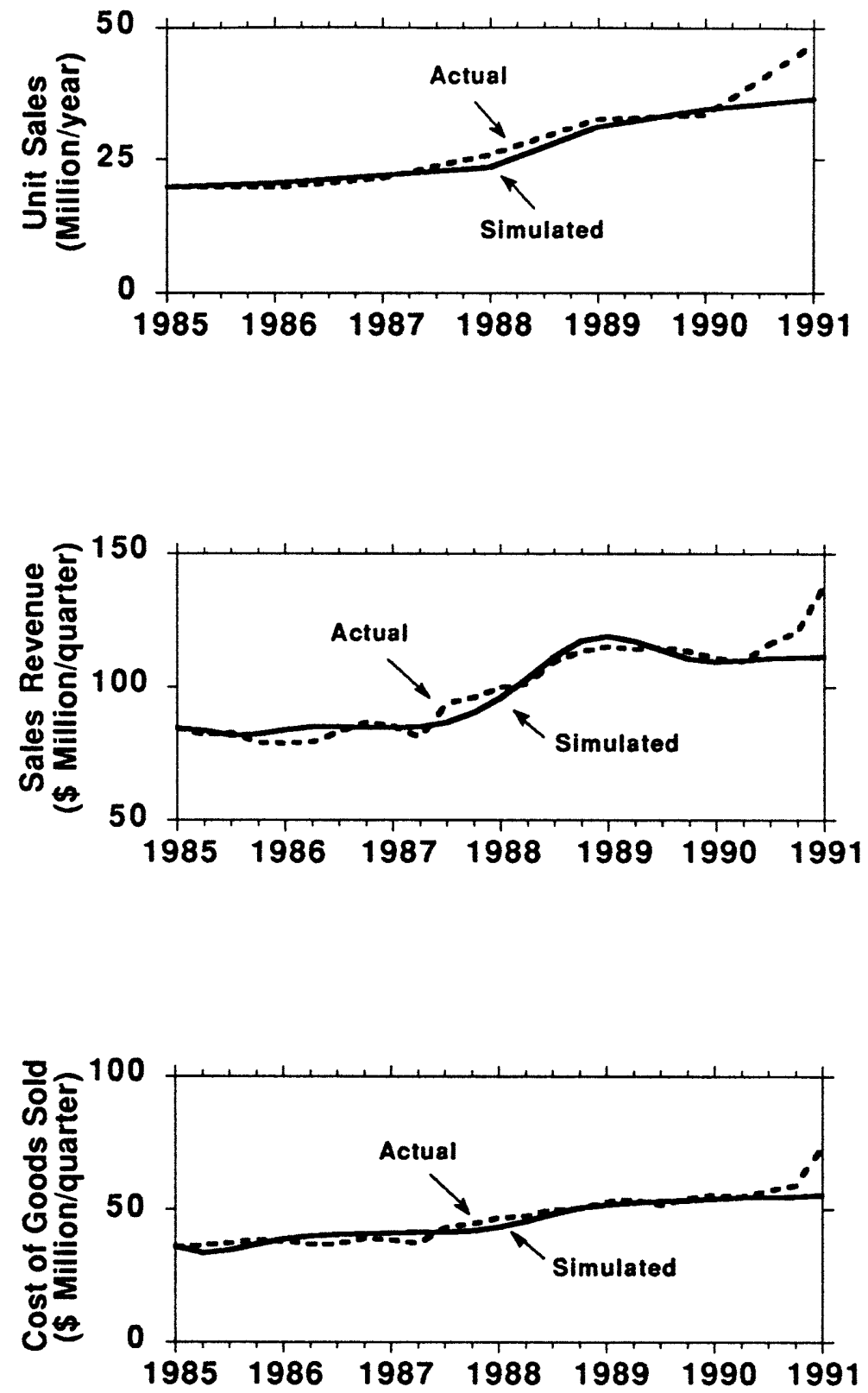

Note: The last data points show the impact of the PMI acquisition, raising Analog's sales, revenues, and COGS above the simulated levels for 1991 because the acquisition is excluded from the model. 
Figure 4 (continued). Comparison of simulated and actual data: Sales and Financial metrics
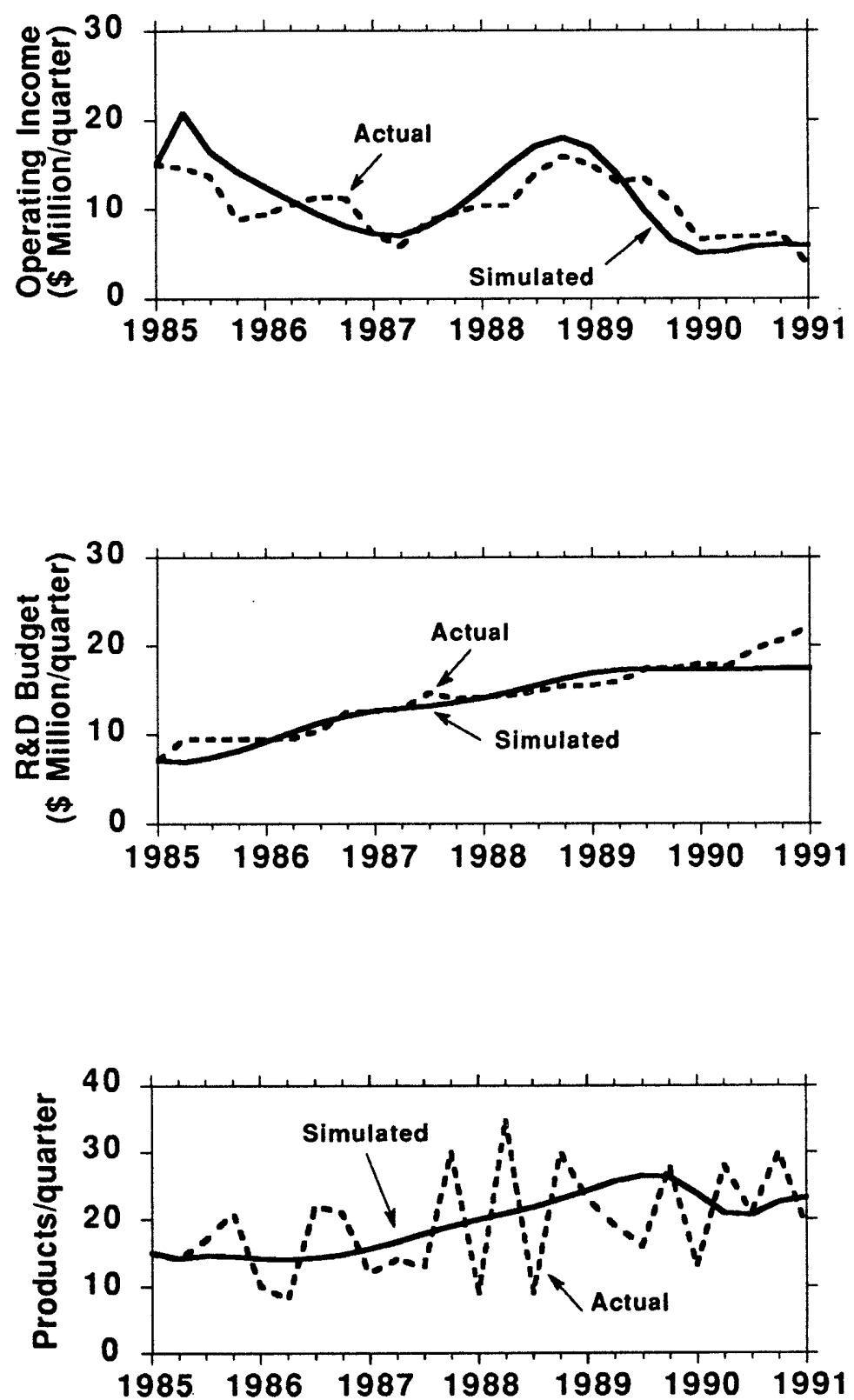
Figure 4 (continued). Comparison of simulated and actual data: Sales and Financial metrics
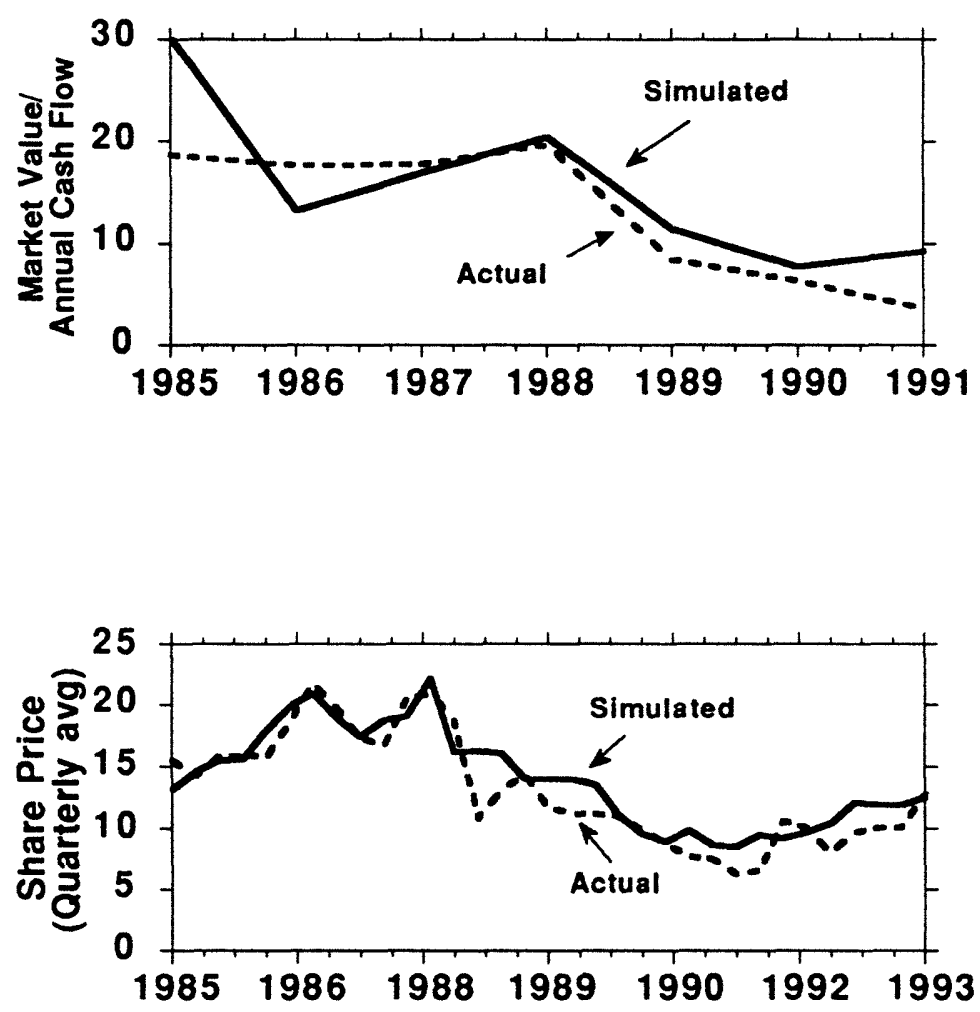
Figure 5. Comparison of simulated and actual data: Quality metrics
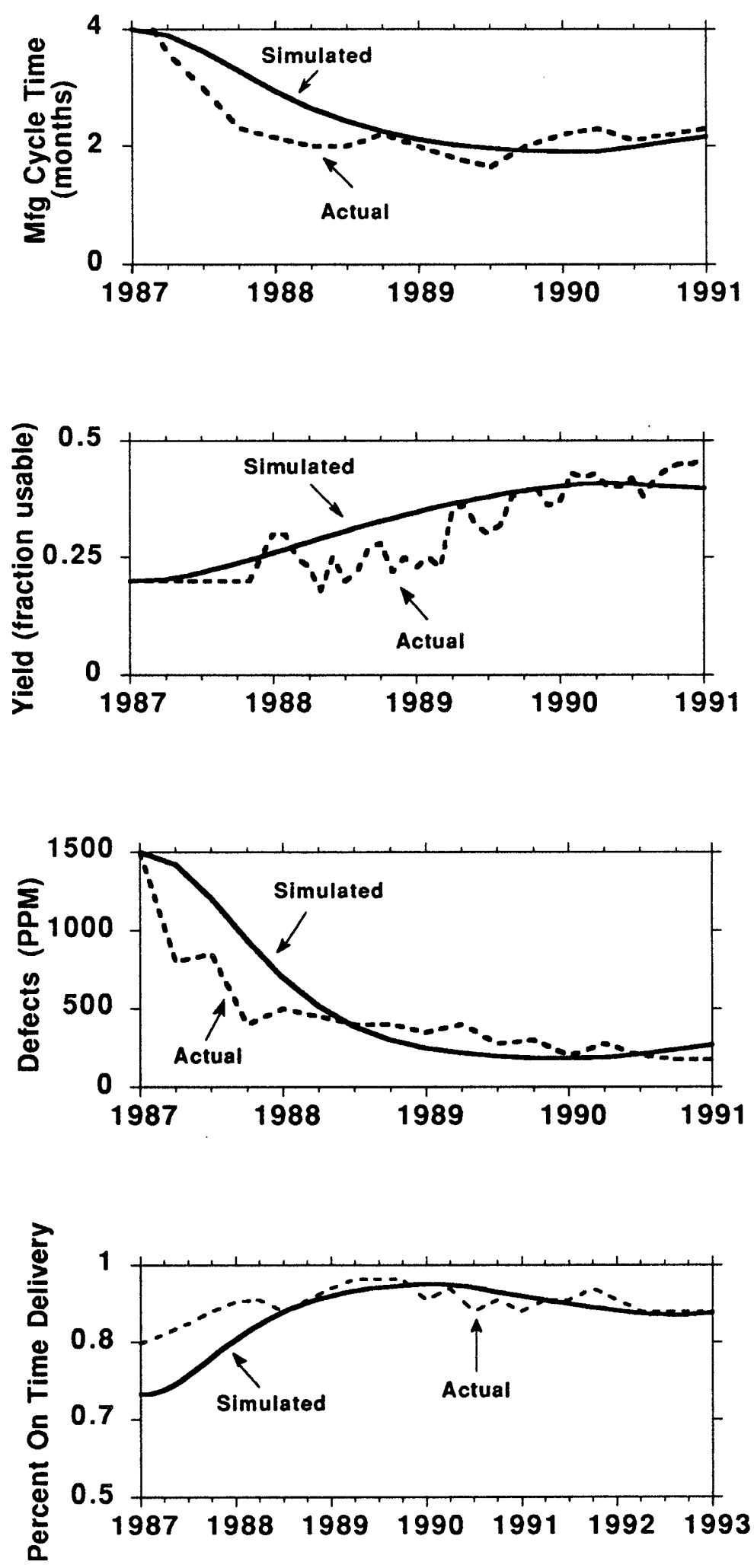
Figure 6a. Base Case: Fraction of workforce committed to TQM.

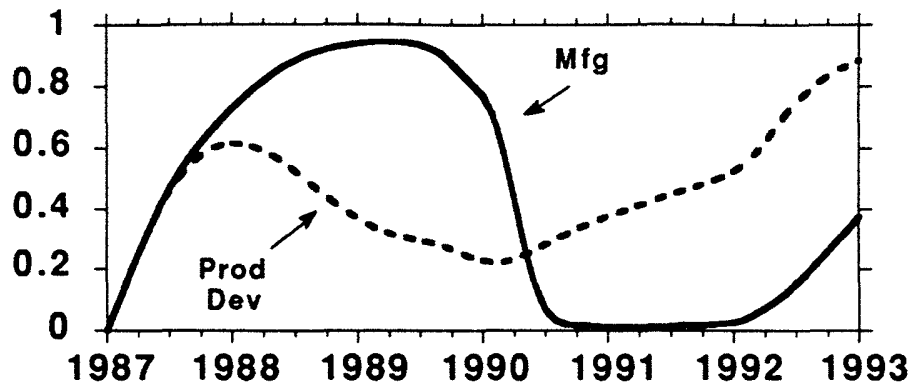

Figure 6b. Base Case: Perceived Job Security $(0=$ no security; $1=$ no layoffs believed possible $)$

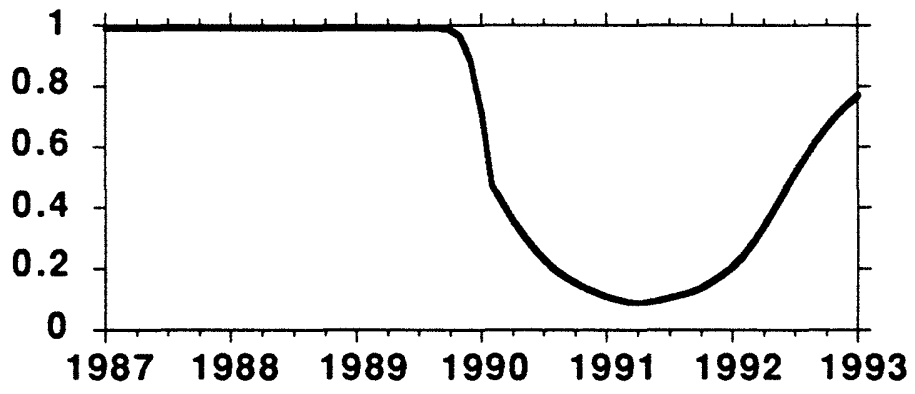

Figure 6c. Base Case: Adequacy of resources to support the TQM program.

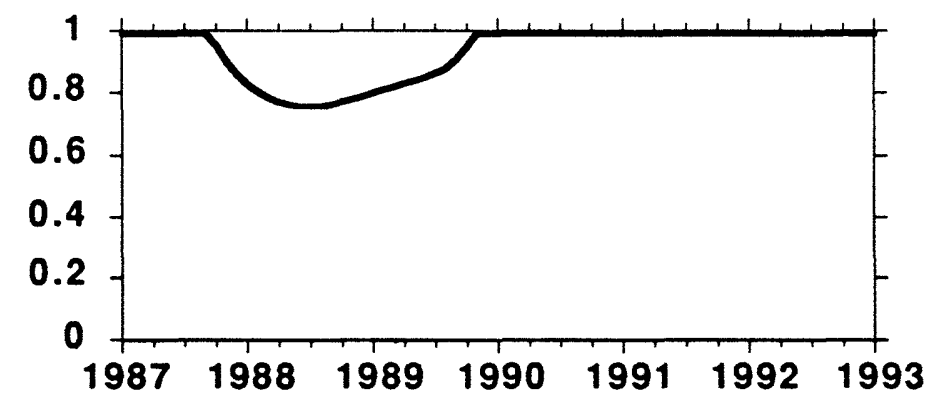

Figure 6d. Base Case: Fraction of TQM support resources allocated to manufacturing.

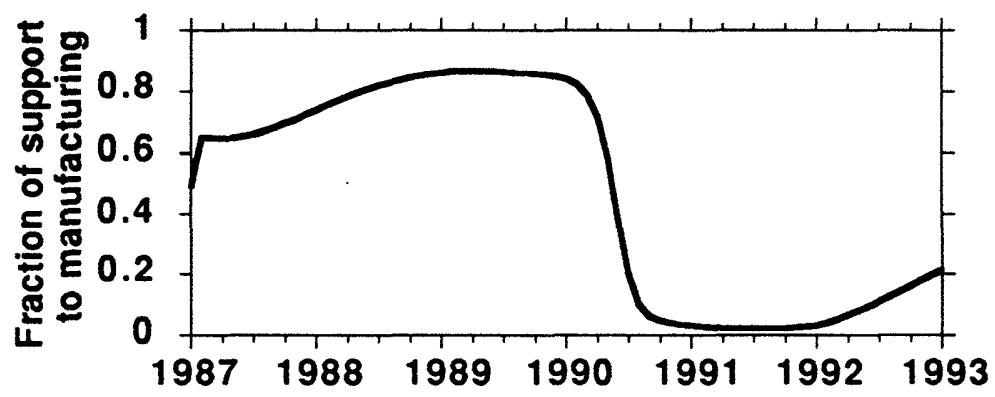


Figure 6e. Base Case: Reported and Target Product Development Time

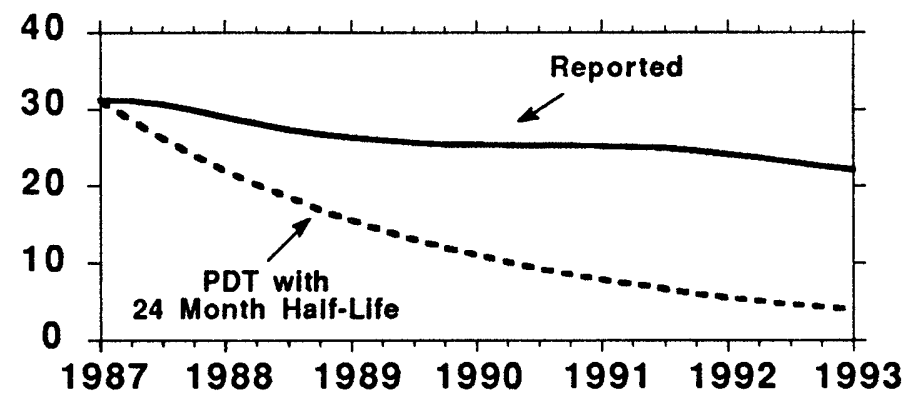

Figure 6f. Base Case: ADI Market Share.

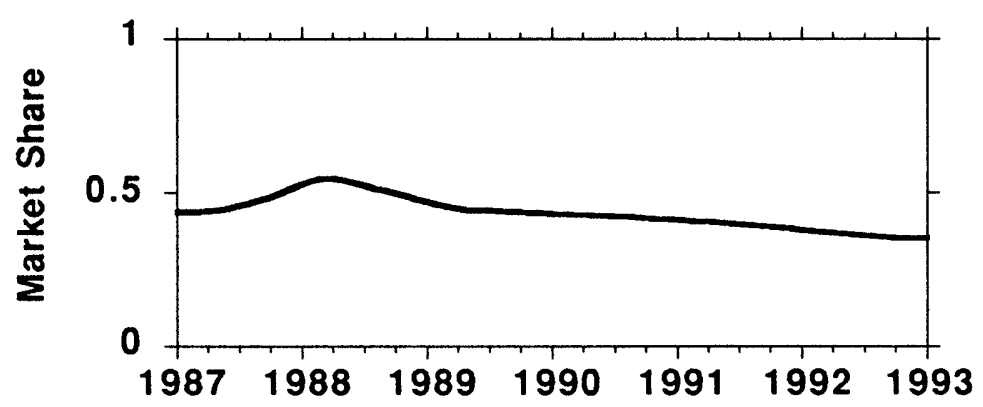


Figure 7a. No-TQM Case: Revenue.

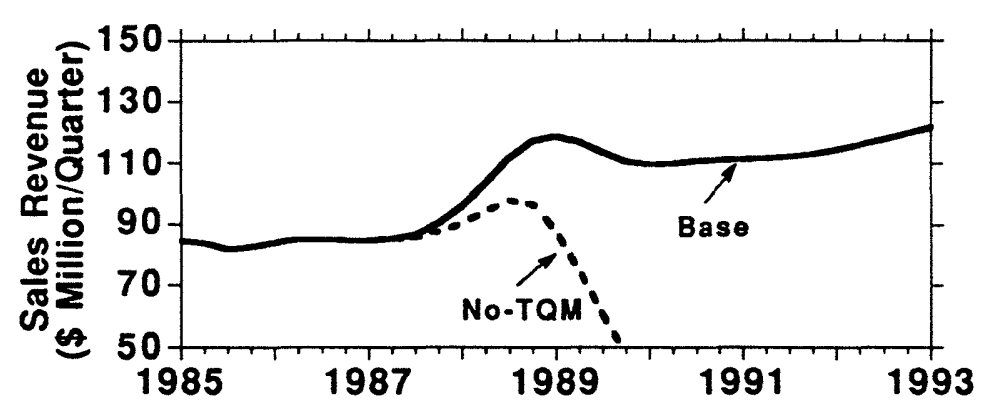

Figure 7b. No-TQM Case: Operating income.

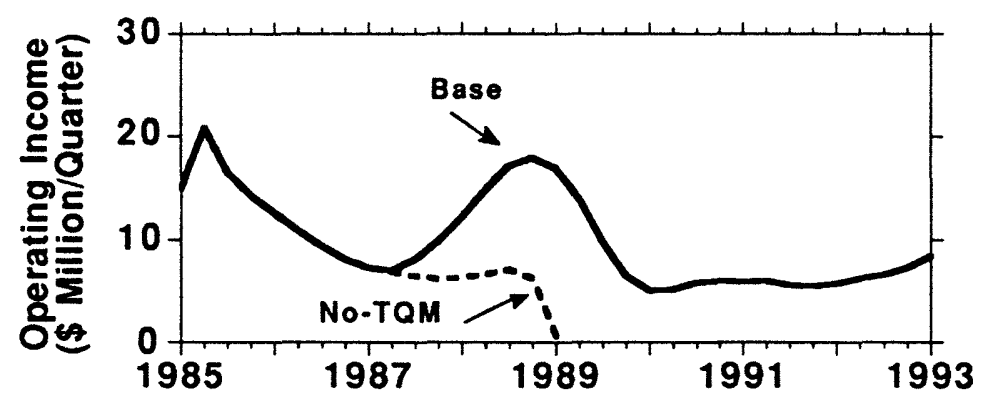

Figure 7c. No-TQM Case: Share price

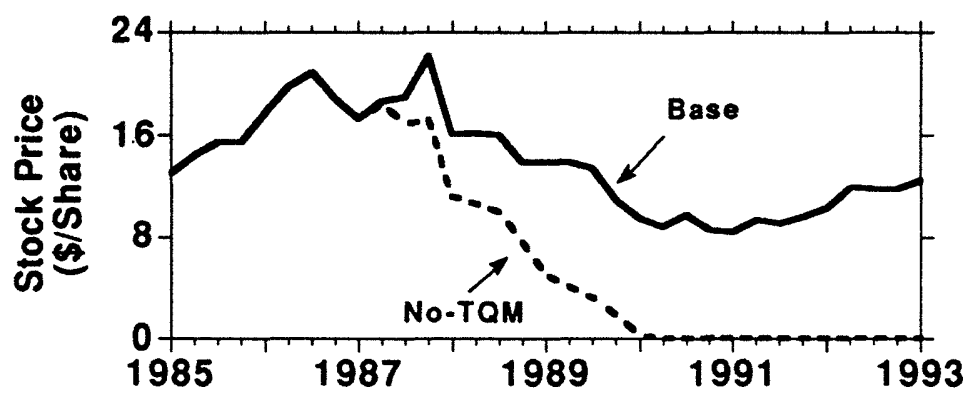


Figure 8. A no-layoff policy causes a Long-term/Short-term tradeoff in financial results.

The 'Wise Layoff' policy, where job cuts have no impact on morale or TQM effort, moderates the tradeoff.

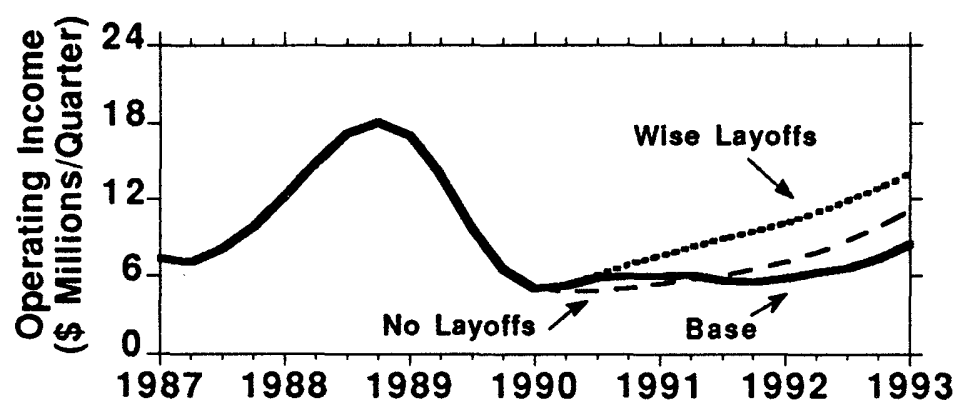

Figure 9. Raising markups to compensate for the slower reduction in indirect costs improves financial performance.
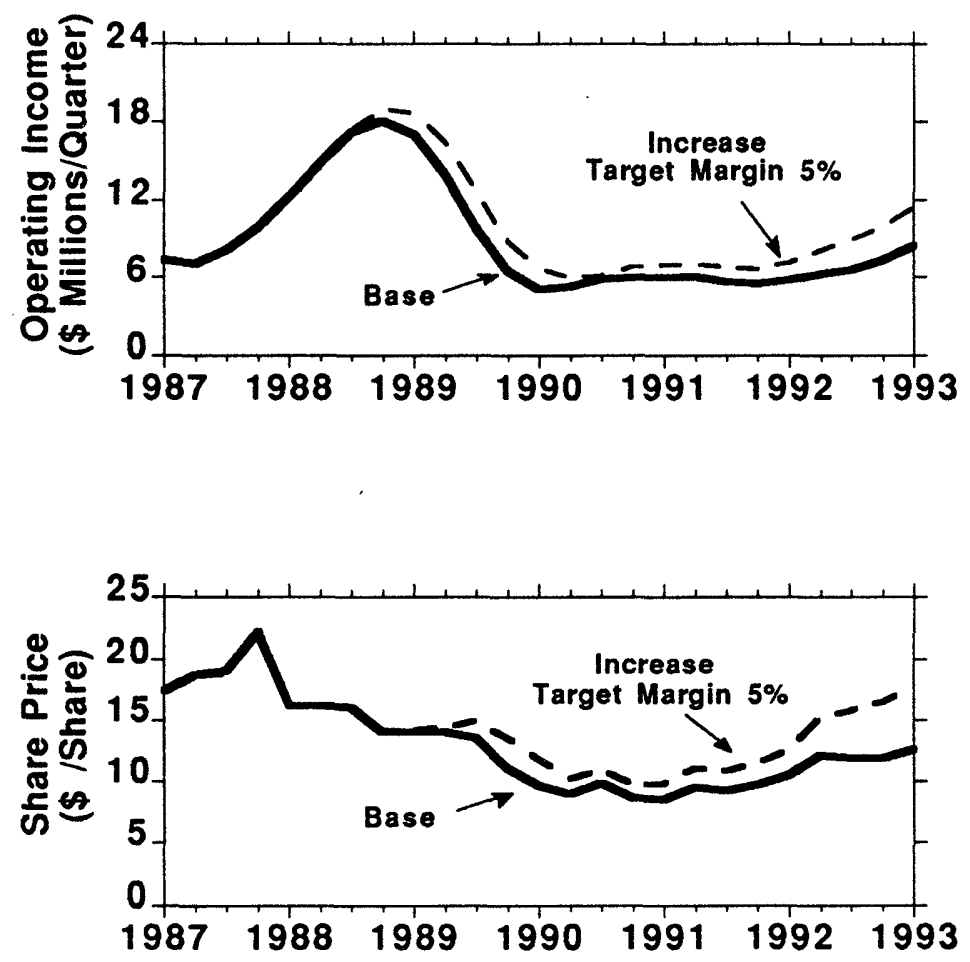